\title{
La crítica de Barragán hacia la publicidad de la vida moderna y su visión sobre la espiritualidad del arte encarnada en su obra arquitectónica: 1940-1980
}

Fernando Curiel Gámez

Recibido: 19-06-2020 | Versión final: 13-03-2021

Resumen La arquitectura que Luis Barragán desarrolló a partir de la década de los años cincuenta es de las manifestaciones arquitectónicas más fieles hacia aquellos indicios que marcaron una tendencia que cuestionaba los postulados ortodoxos de la Arquitectura del Estilo Internacional en México. El siguiente artículo desvela algunos de los postulados teóricos-filosóficos desde donde Barragán criticaba los tiempos modernos y los preceptos éticos-estéticos que impactaron en sus decisiones proyectuales en aquel momento. La investigación llevada a cabo en el archivo de La Fundación de Arquitectura Tapatía Luis Barragán abordó en una primera instancia la biblioteca del arquitecto a partir de un análisis descriptivo de las colecciones de libros y revistas. Dicho análisis permitió elegir cuatro libros cuyos autores fueron frecuentados por Barragán en múltiples ocasiones. Posteriormente se revisaron las transcripciones de las entrevistas hechas al arquitecto mexicano entre 1939 y 1976. Al analizar los contenidos de estas fuentes, dimos cuenta de una relación cercana entre la publicidad de la vida moderna -concepto que el arquitecto mexicano retomó del filósofo español José Gaos en sus entrevistas- y las múltiples nociones teóricas-filosóficas que Barragán leía en torno a la preponderancia de la vida pública sobre la privada y la angustia. Adicionalmente, los contenidos de estos autores coincidían en el papel de la espiritualidad del arte y su pertinencia en aquel momento histórico. El artículo hace una exposición de estos contenidos para finalmente deducir conclusiones que trazan las posibles rutas biográficas-intelectuales que se concretaron en ciertas cualidades espaciales propias de la arquitectura que Barragán desarrolló en ese momento.

Palabras clave: Existencialismo; angustia; arquitectura moderna mexicana

Citación

Curiel Gámez, F. (2021). La crítica de Barragán hacia la publicidad de la vida moderna y su visión sobre la espiritualidad del arte encarnada en su obra arquitectónica: 1940-1980, ACE: Architecture, City and Environment, 16(47), 9051. DOI: http://dx.doi.org/10.5821/ace.16.47.9051

\section{Luis Barragán’s Criticism Towards the Publicity of Modern Life and his Vision Concerning the Spirituality of Art Embodied in his Architectural Work: 1940-1980}

Abstract

\begin{abstract}
The Architecture developed by Luis Barragán from the 1950's is one the most truthful architectonic expressions to those evidences that marked the beginning of an inclination which questioned the International Style Architecture's orthodox postulates in México. The next article unveils some of the theoretical-philosophical postulates from which Barragán criticized modern times and the ethicalesthetical precepts embodied in his architectural work during that moment. The present research work developed at Fundación Tapatía de Arquitectura Luis Barragán started with a descriptive analysis of Luis Barragán's principal books' collections and magazines. This analysis allowed selecting four books whose authors Barragán frequented on several occasions. Afterwards, transcripts of interviews done to Barragan, especially those realized between 1939 and 1976, were reviewed. The analysis of all these sources allowed to detect a relation between the publicity of modern life - a concept Barragán took from the Spanish philosopher José Gaos several times in his interviews- and the multiple theoreticalphilosophical ideas that Barragán highlighted in his books read about the prevalence of public life over the private one and about angst. In addition, concepts mentioned by these authors matched with the idea of the spiritual role of arts and its relevance at that historical moment. This article exposes all these contents and traces conclusions about some hypothetical biographical-intellectual routes which were embodied in certain spatial qualities of Luis Barragán's work since 1950’s.
\end{abstract}

Keywords: Existentialism; angst; Mexican modern architecture

${ }^{1}$ Dr. Arquitecto, investigador y profesor de tiempo completo en la Escuela de Arquitectura, Arte y Diseño del Tecnologico de Monterrey. (ORCiD: 0000-0002-5967-8401; WoS ResearcherID: AAE-6520-2020). Correo de contacto: fcuriel@tec.mx

ACE, 16 (4.7) CC BY-ND 3.0 ES | UPC Barcelona, España | La crítica de Barragán hacia la publicidad de la vida moderna y su visión sobre la espiritualidad del arte encarnada en su obra arquitectónica: 1940-1980. DOI: http://dx.doi.org/10.5821/ace.16.47.9051 


\section{Introducción}

La obra de Luis Barragán es, quizás, de las arquitecturas mexicanas más documentadas del siglo XX. Buena parte de estas publicaciones explican a detalle su arquitectura, el contexto desde donde se edificó y los postulados teóricos y filosóficos que la respaldó. Adicionalmente, existen numerosas entrevistas realizadas al arquitecto mexicano entre los años cuarenta y ochenta publicadas por diferentes revistas de arquitectura en México y en el ámbito internacional. Algunas de las copias transcritas de estas entrevistas han sido conservadas por la Fundación Tapatía de Arquitectura Luis Barragán. ' Toda esta documentación es de alto valor, ya que son pocas las fuentes donde Barragán explicaba su obra arquitectónica de manera personal. Adicionalmente, la misma fundación conserva la biblioteca de Luis Barragán. ${ }^{2}$

A pesar de los diversos traslados que tuvo este acervo después de la muerte del arquitecto mexicano, las condiciones físicas de los libros y revistas se encuentran de forma íntegra. Al igual que la documentación del archivo personal, la biblioteca personal es de suma importancia para abordar a la figura de Luis Barragán desde una visión multidisciplinar, ya que esta fuente funge como testimonio de la diversidad de horizontes culturales que sin duda alguna contribuyeron en el imaginario y pensamiento del arquitecto mexicano.

Al analizar las transcripciones de las entrevistas, llama la atención una preocupación particular desde la cual parte buena parte del fundamento teórico de Barragán, específicamente, el sesgo existente entre la vida pública y privada del hombre debido a la publicidad de la vida moderna.

Para Barragán la ciudad moderna representaba una amenaza a la integridad emocional y espiritual del habitante. El estilo de la vida moderna en la ciudad provocó serios cambios en los usos y costumbres de sus habitantes. Ya desde 1951, en su conferencia impartida en el California Council of Architects y la Sierra Nevada Regional Conference en Coronado, California, titulada Gardens for Environment: Jardines de El Pedregal (Figura 1), Barragán hablaba de esta problemática y argumentaba que la causa de esta situación había sido la sustitución de la vida privada por la pública a causa de la vida de publicidad. Según el maestro mexicano, la mayor parte de las personas se habituaron a comer y a cenar lejos de su hogar; durante las vacaciones frecuentaban los clubes, bares o cines; y, por lo general, estaban expuestos constantemente a los medios de comunicación masiva como son la radio, la televisión y el teléfono. (Barragán, 1951)

Posteriormente, en una entrevista hecha en 1962, Barragán mantenía su postura sobre el impacto de las hostilidades provocadas por la ciudad moderna hacia la vida privada. Al respecto, el arquitecto comentaba lo siguiente: "Ya hay la costumbre de hacer el week end, y el week end no se hace sólo, se hace con un grupo de gente, es decir en todo esto hay algo de publicidad. No publicidad para exhibirse, sino que ya no es la vida íntima, la vida interior, sino que es la vida en hoteles o en lugares de recreo o en una serie ininterrumpida de fiestas. Al respecto, sobre lo que es publicidad en nuestra vida, hay mucho que decir." (Ramírez, 1962, pág. 11)

\footnotetext{
${ }^{1}$ Para efectos del presente artículo se revisaron las siguientes entrevistas: Mexican Journal. The Conquerors Conquered (1958), publicado por Selden Rodman en “The Devin-Adair Co"; Luis Barragán y el regreso a las fuentes (1975), entrevista realizada por Damián Bayón para la "Revista Plural". Todas estas entrevistas fueron consultadas en Antonio Riggen Martínez, Luis Barragán: Escritos y Conversaciones. Las entrevistas llevadas a cabo por Alejandro Ramírez Ugarte (1962) y Clyve Bamford Smith (1968) titulados Los Jardines de Luis Barragán y Luis Barragán. Entrevista sobre el Cuestionario, respectivamente, fueron consultados en el archivo de la Fundación Tapatía de Arquitectura Luis Barragán. Y finalmente, la entrevista que le hizo la periodista Elena Poniatowska a Barragán fue consultada en Todo México. Volumen 1, 1996.

2 Sobre la Biblioteca de Luis Barragán existen algunos de textos que abundan brevemente en las colecciones de libros y autores de cabecera del arquitecto mexicano. El primero de ellos es Voces de tinta dormida: itinerarios espirituales de Luis Barragán de Alfonso Alfaro y Tres Visitas a la Biblioteca de Barragán, de Álvaro Mutis, Vicente Quirarte y Jorge Esquinca, ambos publicados en la Revista Artes de México en 1999. Por otro lado, está también En busca de Luis Barragán de María Emilia Orendain del 2004.
}

ACE, 16 (4.7) CC BY-ND 3.0 ES | UPC Barcelona, España | La crítica de Barragán hacia la publicidad de la vida 2 moderna y su visión sobre la espiritualidad del arte encarnada en su obra arquitectónica: 194.0-1980. DOI http://dx.doi.org/10.5821/ace.16.47.9051 
Figura 1. Luis Barragán y Carlos Contreras en el California Council of Architects y la Sierra Nevada Regional Conference en Coronado, California, 1951

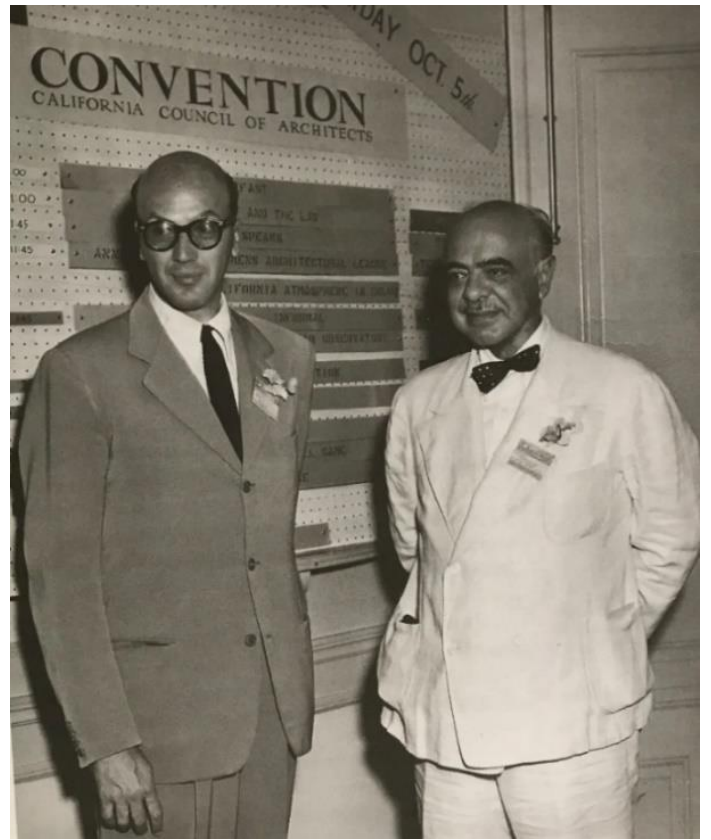

Fuente: Archivo Personal Luis Barragán. Fundación de Arquitectura Tapatía Luis Barragán

Según Barragán, la publicidad propició a su vez un decaimiento en la autenticidad de las relaciones humanas y de la vida íntima, debido a una especie de vida de publicidad falsa (Ramírez, 1962). Más adelante, en 1975 Barragán reiteraba sus convicciones respecto a la publicidad, pero en esta ocasión, atribuía el uso de este concepto al filósofo español José Gaos: "Yo recuerdo ahora una conferencia que dio aquí en México el filósofo José Gaos, (...) en la que se refirió a la publicidad de nuestra vida debido, entre otras cosas, a la ausencia de intimidad en las casas y jardines. Por supuesto no era sino una crítica a nuestra vida actual, a esa manía de la gente que necesita salir siempre fuera el fin de semana, frecuentar clubes, vivir en bandas (...). Así que cuando no está fuera, durante el fin de semana, convierten la casa en verdaderos sitios públicos.” (Bayón, 1975, p. 98)

El concepto de [P]ublicidad ${ }^{\beta}$ de Gaos fue parte de un conjunto de reflexiones que formaron parte de los indicios de un proceso de concienciación mundial que cuestionaron severamente los procesos económicos y tecnológicos de un proceso de modernización que había afectado las formas, las expectativas de vida y valores en la sociedad después de la Segunda Guerra Mundial. Dicho término apareció por primera vez en un manuscrito titulado Filosofía de la Filosofía que en un inicio formó parte de un curso que Gaos impartió en la Universidad de Madrid entre 1935- 1936 y posteriormente, en un ciclo de seis conferencias ofrecidas en la Universidad de la Habana en julio de 1938. Meses después, el mismo curso lo dictaba en el paraninfo de la Universidad Autónoma de México. Al haber sido Gaos el principal traductor de la obra Ser y Tiempo (1927) de Martin Heidegger, es muy probable que el filósofo español hubiera fundamentado su concepto de Publicidad en la obra del pensador alemán, quien implementaba el mismo término para explicar los modos del ser impropios en la vida cotidiana. $^{4}$

\footnotetext{
3 Para efectos de este artículo, Barragán adoptó el concepto de Publicidad de José Gaos en diferentes ocasiones para fundamentar su postura crítica de su obra arquitectónica frente a las hostilidades derivadas de la vida moderna. Por ello, se realizará una distinción entre el concepto original de Gaos como Publicidad (con "P” mayúscula al inicio) y publicidad (con "p" minúscula al inicio) cuando nos refiramos al concepto que Barragán implementó.

${ }^{4}$ En la primera sección de hermenéutica de la cotidianidad, Martin Heidegger analiza los modos de ser impropios en la vida cotidiana, como son: las habladurías, tentación, ambigüedad, medianía, publicidad, entre otros más. (Escudero, 2016)
}

ACE, 16 (47) CC BY-ND 3.0 ES | UPC Barcelona, España | La crítica de Barragán hacia la publicidad de la vida moderna y su visión sobre la espiritualidad del arte encarnada en su obra arquitectónica: 194.0-1980. DOI http://dx.doi.org/10.5821/ace.16.47.9051 
No es casualidad que Barragán retomara de José Gaos el concepto de publicidad en su crítica del estilo de vida y la ciudad moderna, ya que ambos mantuvieron una amistad cercana. Sin tener las evidencias suficientes para comprobar la asistencia de Barragán a las conferencias de Gaos en el paraninfo de la Universidad Autónoma de la Ciudad de México en 1938, es evidente que en varias de las entrevistas efectuadas al arquitecto desde 1951 hasta 1977, Barragán se apoyaba en este concepto de la publicidad de Gaos. Adicionalmente, cuando Barragán llegó a la Ciudad de México en 1934, intercambió amistad con una serie de intelectuales mexicanos conscientes de estas inquietudes globales -entre ellos Edmundo O'Gorman y Justino Fernández, quienes a su vez fueron muy cercanos a José Gaos-, situación que le permitió acceder a un ambiente intelectual y a una literatura específica que en aquel entonces prevalecía en los círculos académicos filosóficos e historiográficos.

Para tener una noción de esta literatura, se abordó la biblioteca personal del arquitecto. Al hacer un análisis descriptivo de las colecciones de libros y revistas, se obtuvo un panorama preciso de los temas y autores más frecuentes. Siendo una biblioteca compuesta por cerca de 2200 libros y 600 revistas, en términos generales sus colecciones abarcan temas que van desde el arte, la arquitectura, la literatura, la historia, la filosofía y la antropología. Cerca de un 40\% pertenece al ámbito de las artes plásticas; $20 \%$ a la literatura; $17 \%$ a la arquitectura; $4 \%$ a la historia; $3 \%$ a la religión y el resto pertenece a otras colecciones menores como derecho, geografía, arqueología y filosofía. En cuanto a las revistas, las proporciones son similares. El $41 \%$ de la colección de revistas está dedicada a las artes plásticas; $26 \%$ a la arquitectura; $6 \%$ a los journals y $2 \%$ abarcan temas de cultura general. Además de lo anterior, un rasgo importante de la biblioteca de Barragán es que el 30\% de la colección completa de libros posee marcas de lectura: subrayados, acotaciones, separadores, anotaciones en páginas y encartes.

El análisis descriptivo nos permitió descubrir un interés particular que Barragán tenía hacia ciertos tipos de libros, sobre todo en aquellos cuyos autores y temáticas eran más frecuentes. Así, al centrar la atención en la pequeña colección de filosofía, se eligieron cuatro autores cuyos textos poseen marcas de lecturas y que al analizar los contenidos de los párrafos que Barragán marcaba, se entrevén temas que no nada más mantienen una relación entre sí, sino que también establecen un vínculo importante con el concepto de Publicidad que Barragán retomó del filósofo español José Gaos. Los libros a los que nos referimos fueron escritos por B. Pascal, Ciryl Connolly, A. Huxley y R.P. Sanson, y los temas que Barragán subrayaba y acotaba entres sus páginas abundan en temas como la condición humana; los estragos de la vida moderna como la angustia y la imposibilidad de la existencia auténtica y espiritual; la preponderancia de la vida pública sobre la privada y su imposibilidad para acceder a una vida espiritual. Todos estos temas que Barragán subrayaba en las páginas de estos libros, además de que se relacionaban y ampliaban la visión de Gaos en torno a la Publicidad, coincidían en el rol de la espiritualidad del arte y su pertinencia en la hostilidad de los tiempos modernos.

De esta manera, si regresamos a las afirmaciones que Barragán sostenía en sus entrevistas, pareciera que detrás de ellas yace una reticencia a la mundanidad inmersa en la vitalidad y dinámica que se experimenta propiamente en las ciudades. Pero como veremos más a continuación, las preocupaciones de Barragán en torno a la vida moderna partían desde un fundamento filosófico que iban más allá de lo que aparentaban.

Así, el objetivo que se persigue en este artículo es establecer un diálogo entre los contenidos de los libros de los mencionados autores de la biblioteca personal y el concepto de Publicidad de José Gaos, con el objeto de esclarecer los preceptos filosóficos desde donde Barragán criticaba los tiempos modernos y los preceptos éticos y estéticos desde donde justificaba su arquitectura y paisajismo. Así, a través de este diálogo se intentará esclarecer una posible ruta biográfica-intelectual desde donde Barragán recogía algunos de los tantos indicios de una tendencia mundial de concienciación ante la vida moderna, derivada de los procesos de modernización a partir de la década de los años cincuenta.

ACE, 16 (4.7) CC BY-ND 3.0 ES | UPC Barcelona, España | La crítica de Barragán hacia la publicidad de la vida moderna y su visión sobre la espiritualidad del arte encarnada en su obra arquitectónica: 194.0-1980. DOI http://dx.doi.org/10.5821/ace.16.47.9051 
Para ello, en una primera instancia se realizó una descripción del contexto intelectual desde el momento en que Barragán llegó a la Ciudad de México en 1935 hasta el momento en que entabló amistad con José Gaos. Posteriormente, se llevó a cabo una precisión del concepto de Publicidad del filósofo español para después extrapolarlo con las ideas que Barragán recuperaba de sus autores de cabecera. Más adelante se abundó en las ideas éticas-estéticas que Barragán recuperaba de las páginas de estos libros, mismas que privilegiaban el rol de la espiritualidad del arte sobre la Publicidad de la vida moderna. Y para finalizar se analizaron algunos ejemplos de la arquitectura doméstica del arquitecto mexicano, puntualizando en aquellas cualidades espaciales que hipotéticamente partieron de la postura crítica de Barragán hacia la Publicidad de la vida moderna.

\section{Contextos}

La visión de Luis Barragán sobre la vida moderna no siempre se mantuvo igual. Tras una intensa actividad profesional en la ciudad de Guadalajara, el arquitecto tapatío decidió trasladarse a la Ciudad de México en 1934. Para este entonces, Barragán visualizaba la capital del país como el centro del futuro, del desarrollo científico e industrial, sin perder de vista la importancia de las enseñanzas de los antiguos. Y quizá haciendo una paráfrasis del libro Vers une architecture de Le Corbusier ${ }^{5}$, Barragán mencionaba lo siguiente: "El espíritu de hoy llama a la pureza, al rigor, al mejor uso de la materia. La belleza de una época debe surgir de la solidaridad del arte con este espíritu.” (Barragán, 1932, pág. 19)

El vigory la velocidad con la que acontecía la vida moderna en la Ciudad de México habían seducido al arquitecto tapatío. Por ello, la arquitectura desarrollada por Barragán en la Ciudad de México hasta antes de la década de los cuarenta, llegó ser afín a las convicciones puristas de Le Corbusier y Gropius.

Pese a ello, en ese entonces la visión de la vida moderna de Barragán se vio atenuada en el momento que entró en contacto con el clima intelectual de la capital mexicana. En esta misma década, en el ámbito del pensamiento mexicano prevalecía un claro sesgo entre los intelectuales alineados a las doctrinas filosóficas de Samuel Ramos, quien lideraba el grupo de Los Contemporáneos y, por el otro lado, la línea del pensamiento político materialista y socialista impulsada por el régimen presidencial de Lázaro Cárdenas. En el caso de Samuel Ramos y su grupo, entre sus aportaciones más importantes al pensamiento mexicano fue la introducción del pensamiento existencial y fenomenológico alemán en el ámbito académico en México. (Romanell, 1952)

Dicho proceso fue complementado por la presencia de la doctrina filosófica de José Ortega y Gasset, cuyas obras fueron publicadas desde la década de los años veinte en México, así como también La Revista de Occidente, dirigida por el propio pensador español. Gracias a las reseñas y trabajos de traducción llevadas a cabo por los integrantes de la misma revista, se dieron a conocer en México autores como Jung, Scheler, Simmel, Hegel, Brentano, Spranger, Sombart, entre otros más (Garciadiego, 2016).

Barragán estuvo muy cercano a este proceso de neo-orteguización del pensamiento mexicano en el momento en que llega a la Ciudad de México, ya que mantuvo amistad cercana con dos académicos claves durante este proceso: el historiador Edmundo O'Gorman (Figura 2) y el historiador del arte Justino Fernández. ${ }^{6}$

5 Entre la multiplicidad de publicaciones que Barragán conservó de Le Corbusier de esta época tenía: Vers une architecture
(1925), L'art décoratif d'aujourd'hui (1925), Urbanisme (1924), Précisions sur un état présent de l'architecture et l'urbanisme
(1930) y Quand les cathédrales étaient blanches (1937).
${ }^{6}$ La amistad entre Luis Barragán y Justino Fernández se remonta desde 1939, ya que fue a través de Barragán como el
historiador del arte conoció a José Clemente Orozco. "Conocí a Orozco personalmente en 1939 un día en que me presentó
a él, en el restaurante Prendes, el arquitecto Luis Barragán (Fernández, 1983, pág. 115)". Asimismo, la amistad de Barragán a kl, en el restaurante Prendes, el arquitecto Luis Barragán (Fernández, 1983, pảg. 115)". Asimismo, la amistad de Barragán

ACE, 16 (4.7) CC BY-ND 3.0 ES | UPC Barcelona, España | La crítica de Barragán hacia la publicidad de la vida 5 moderna y su visión sobre la espiritualidad del arte encarnada en su obra arquitectónica: 194.0-1980. DOI: http://dx.doi.org/10.5821/ace.16.47.9051 


\section{ACE Architecture, City and Environment}

E-ISSN 1886-480:5

Figura 2. De izquierda a derecha: Luis Barragán, Alfonso Pallares y Edmundo O’Gorman

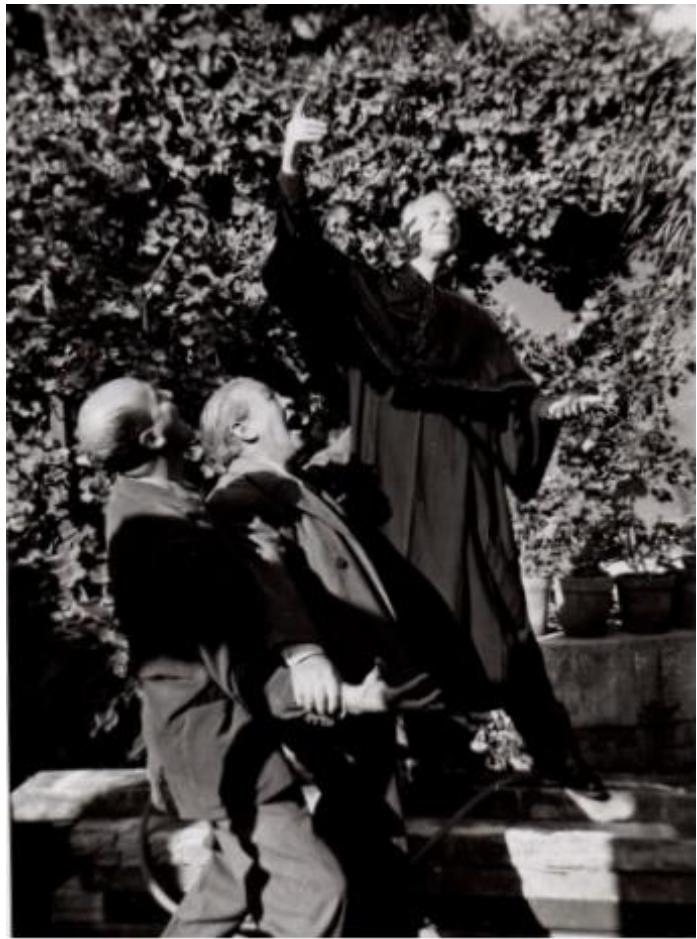

Fuente: Archivo Personal Luis Barragán. Fundación de Arquitectura Tapatía Luis Barragán

Por otro lado, Barragán se mantuvo cercano con el clima intelectual español cuyos integrantes habían llegado a México a mediados de la década de los años treinta. Debido a la Guerra Civil Española que acontecía en aquellos días, Daniel Cosío Villegas -que en 1934 fundó la casa editorial Fondo de Cultura Económica-, realizó las solicitudes formales al gobierno mexicano para invitar a autores como José Gaos, Eduardo Nicol, Juan Roura-Parella, José Medina Echeverría, Joaquín Xirau y Juan David García Bacca. Todos ellos se instalaron progresivamente en las universidades de México, y, en el caso de Gaos, García Bacca y otros exiliados españoles como Gallegos Rocafull y Millares Carlo, trabajaron como traductores en el Fondo de Cultura Económica.

A José Gaos se le reconoce haber sido un gran lector y traductor de las obras filosóficas de Martin Heidegger. En 1938, a pocos meses de su llegada a México, el filósofo español comenzó la traducción de la obra Ser y Tiempo para el Fondo de Cultura Económica. Al mismo tiempo, Gaos inició sus labores docentes en la Universidad Autónoma de México. Era de esperar que el trabajo de la traducción del filósofo alemán permeara en su doctrina filosófica que transmitió semanalmente a sus alumnos (Garciadiego, 2016). Cercanos a este mismo círculo filosófico académico trabajaban Edmundo O'Gorman y Justino Fernández, por lo que es probable que como fruto de esta cercanía naciera la amistad entre José Gaos y Barragán. ${ }^{7}$

con este intelectual del arte siguió por los años cuarenta, ya que construyeron junto con el arquitecto Enrique del Moral, una casa dúplex ubicada en la Ciudad de México (Noelle, 1996).

7 De hecho, además de acudir a las conferencias de Gaos -como bien menciona Barragán en la entrevista con Damián Bayón en 1975- el arquitecto mexicano estuvo atento a las publicaciones de José Gaos. Lo anterior se verifica en una introducción que escribe el propio Barragán para un compendio de sentencias filosóficas titulado Cena de los Aforismos de 1958: "En la Navidad de 1957 invité a cenar a mi casa a María Luisa Lacy, Gloria Cándano, Justino Fernández y Edmundo O’Gorman para escuchar, de labios del autor, la lectura del Diez por Ciento [ejemplar que Barragán tenía en su biblioteca], la colección de aforismos, entonces recién aparecida, de José Gaos." La publicación que realizó Luis Barragán de La Cena de los Aforismos fue parte del compromiso adquirido por el propio arquitecto, una vez que se acordó entre los miembros de repetir el coloquio para la Navidad de 1958. La Cena de los Aforismos sería entonces el compendio de las sentencias

ACE, 16 (47) CC BY-ND 3.0 ES | UPC Barcelona, España | La crítica de Barragán hacia la publicidad de la vida moderna y su visión sobre la espiritualidad del arte encarnada en su obra arquitectónica: 194.0-1980. DOI: http://dx.doi.org/10.5821/ace.16.47.9051 
En 1938 -año en que José Gaos se establece en México- Barragán escribía algunas ideas personales en torno a la arquitectura mexicana. Para ello, criticaba la arquitectura de Richard Neutra, que desde su punto de vista estaba exenta de un análisis profundo de los aspectos humanos (Barragán, 1938). A cambio Barragán opinaba lo siguiente: "[l]a vida es muy diferente en todas partes, las costumbres, las religiones, los climas, todo. (...) Hay que revisar las cosas, pero sobre todo las nuevas necesidades de la vida moderna." (Barragán, 1938, pág. 21)

Como producto de estas preocupaciones arquitectónicas, Barragán construyó en 1940 la Casa Villaseñor en San Ángel. En esta obra se constataba un primer intento por alejarse de las doctrinas puristas y racionalistas ortodoxas modernas, para abrir paso a una arquitectura que conciliara los aspectos funcionales con los aspectos humanos y regionales. Es probable que el contacto de Barragán con el círculo académico de pensadores mexicanos y españoles contribuyó en el reforjamiento de sus convicciones respecto a la modernidad.

De ahí que, entre 1943 a 1951 Barragán construyó tres viviendas (Casa-Ortega de 1943, Casa-Estudio de 1947 y la Casa Prieto López de 1949-1951), las cuales plantearon rotundos cambios en el lenguaje arquitectónico y en la relación espacio doméstico/paisaje natural. Era evidente que, para este momento, Barragán había finalmente establecido una línea de trabajo respaldada por un bagaje éticoestético que confrontaba a la arquitectura del Estilo Internacional, mismo que se reflejaba en la mencionada conferencia en Coronado de 1951, a partir de sus consideraciones críticas sobre la publicidad de la vida moderna.

\section{Gaos y la Publicidad}

"El desplazamiento del hombre por la máquina sólo ha sido posible tras la mecanización del trabajo mismo del hombre. El totalitarismo del Estado, sólo tras haberse hecho pública la vida entera, a costa de la privada e intima." (José Gaos, “XC Al arquitecto Luis Barragán”, del libro Diez por ciento, 1957.) $)^{8}$

Para José Gaos resultaba imprescindible esclarecer la naturaleza esencial del proceso de secularización de la vida humana que tendría su máxima expresión en los regímenes políticos totalitarios en la época moderna a mediados del siglo XX. En 1944 siendo profesor ordinario de la Facultad de Filosofía de la Universidad Nacional Autónoma de México, Gaos impartió un curso que denominó Metafísica. Para el filósofo, el paso del catolicismo al inmanentismo (la ausencia de Dios en la vida humana) posibilitó el auge del Totalitarismo en la sociedad moderna. Este fenómeno fue posible gracias a la anulación progresiva de la vida privada de los seres humanos.

De igual forma en que M. Heidegger indagaba en la analítica existenciaria del dasein en Ser y Tiempo, Gaos detectaba la primacía existente de la visión técnica-física en la vida contemporánea. El filósofo español criticaba cómo estas prioridades favorecieron en la multiplicación de las formas de comunicación, en las situaciones vitales, en los quehaceres y en la afectación de la función de la profundidad de su vida. La superficialidad de la vida técnica física que prevalecía en el mundo contemporáneo vaciaba y desentrañaba progresivamente no solo a la vida, sino a la naturaleza y al mundo entero, "de toda hondura, de toda intimidad, de pasiones, y de placeres profundos, de todo misterio, (...)." (Gaos y Larroyo, 1940, pág. 11)

filosóficas dictadas del ingenio de los asistentes a lo largo de 1958, para ser leídas durante la cena de Noche Buena de ese año.

8 En el ejemplar de Barragán del libro Diez por ciento, a modo de dedicación, el autor José Gaos escribía lo siguiente: "Ejemplar no. 2, para Luis Barragán. Con agradecimiento a sus jardines y admiración a sus afecciones. (...) Felices Navidades de 1957 y Año Nuevo de 1958. José Gaos."

ACE, 16 (4.7) CC BY-ND 3.0 ES | UPC Barcelona, España | La crítica de Barragán hacia la publicidad de la vida 7 moderna y su visión sobre la espiritualidad del arte encarnada en su obra arquitectónica: 1940-1980. DOI http://dx.doi.org/10.5821/ace.16.47.9051 
En contraste con lo anterior, para el filósofo hubo un momento en la historia de la humanidad en que la vida de los seres humanos mantuvo una presencia auténtica con la vida trascendental. Para el cristiano, significaba la presencia de Dios desde la intimidad de su vida y se hacía evidente desde los siguientes aspectos: la experiencia de la propia vida en relación íntima con lo trascendente y lo supra-racional a partir del acto imaginativo individualizado; la constatación de esa realidad trascendente no tanto en el propio mundo, sino en la solitaria intimidad de la persona; y finalmente, la experiencia de la muerte como vínculo hacia esa realidad que está más allá de lo inmanente. (Cuervo, 2016)

Con el paso del tiempo, según Gaos, el hombre cristiano disolvió la presencia de Dios al focalizar su atención en lo inmanente, en el mundo real, a partir de sus actos dictaminados por su propia razón. Esto impidió los necesarios actos imaginativos que propiciaban la experiencia de lo trascendente por lo inmanente. Al respecto Gaos decía lo siguiente: "las personas pierden como los muros imaginativos - de su aislamiento- quedan no aisladas- sino sin morada interior-sin casa- en la plaza pública-en público- en literal comunidad." (Gaos, 1993, pág. 50) Este proceso absorbente de la vida privada e íntima por la pública, Gaos la denominó como Publicidad.

Y finalmente, en la vida pública, la atención exacerbada hacia el mundo real, a través los sentidos, contribuye en la banalización progresiva de la vida humana y en su propio deleite. Para Gaos, los placeres, las diversiones y la mundanidad son ahora fines en sí mismos; la soledad y la intimidad que condicionaban las posibilidades para afrontar la finitud y condición mortal de la humanidad a la que se teme y por la que se sufre, se evaden constantemente (Cuervo, 2016).

Con estas puntualizaciones expuestas respecto al concepto de Publicidad de José Gaos, se hace evidente la relación cercana que mantiene en cuanto a su contenido con el concepto de publicidad que Barragán retomó del filósofo. En una conversación que sostuvo el arquitecto mexicano con la periodista Elena Poniatowska en 1976, Barragán insistía en cómo la vida moderna había hecho perder la privacía de los seres humanos. "[C]omo arquitecto quisiera encontrar la fórmula para que el hombre se tranquilizara en su casa, se repusiera de las agresiones de la ciudad." (Poniatowska, 1996, pág. 24) Un arquitecto debía ser para Barragán un artista que lograra alejar la ansiedad y crear ilusiones para el habitante de su arquitectura. Los contenidos de los libros de cabecera que se eligieron de la colección de filosofía de la biblioteca personal no solo aclaran el proceso absorbente de la vida privada por la pública que le preocupaba a Gaos, sino también responden a las preocupaciones de Barragán por alejar la ansiedad a través de la creatividad y la espiritualidad del arte.

\section{Las lecturas de Barragán}

Como se mencionó anteriormente, la colección de libros de Barragán consagrados a la literatura y a la filosofía corresponden a un poco más de un 20\% del total de volúmenes. Resaltan las obras de autores clásicos de la literatura moderna como Baudelaire, Stendhal, Reverdy, Valery, Proust (Figura 3), Mauriac, Valle-Inclán, Claudel y Maurois; y del ámbito de la filosofía destacan los libros de Ortega y Gasset, Pascal, Huxley, Croce, Unamuno, Marco Aurelio, Connolly, entre otro más. En varios de los títulos de estos autores se localizaron abundantes marcas de lecturas que se focalizan en múltiples temas y preocupaciones que profundizan en aspectos como el amor, la existencia, el arte, la vida espiritual y la condición humana. ${ }^{9}$

\footnotetext{
9 Juan Palomar Vera, quien ha sido de los principales responsables de la conformación y procuración del archivo y biblioteca de Luis Barragán, mencionaba que las marcas de lectura que presentan los libros y revistas son parte de las evidencias de la relación "cuerpo a cuerpo" que Barragán mantenía con su biblioteca. Al respecto, comentaba lo siguiente: "Hay muchos libros que tienen marcas de lectura y de lectura reiterada. Hay subrayados en la primera lectura con un color, en la segunda con otro color, en la tercera anotaciones, dobleces, encartes, señales. Era como que encontraba
} moderna y su visión sobre la espiritualidad del arte encarnada en su obra arquitectónica: 194.0-1980. DOI http://dx.doi.org/10.5821/ace.16.47.9051 
Figura 3. Transcripciones realizadas por Luis Barragán de fragmentos de la obra de Marcel Proust, septiembre de 1969

"...dans un monde oú l'amour n'est provoqué que par le mensonge et consiste seulement dans notre besoin de voir nos souffrances apaisées par

l'être qui nous a fait souffrir?

Proust La Prisonnière

(...)Et comme on comprend que la souffrance est la meilleure chose que l'on puisse rencontrer dans la vie, on pense sans effroi, presque comme à une délivrance, à la mort.

(...) les chagrins sont des serviteurs obscurs détestés, contre lesquels on lutte, sous l'empire de qui on tombe de plus en plus, des serviteurs atroces, impossibles à remplacer et qui par des

voies souterraines nous mènent à la vérité et à la mort. Heureux ceux qui ont rencontré la première avant la seconde, et pour qui, si proches qu'elles doivent être l'une de l'autre, l'heure de la vérité a sonné avant l'heure de la mort. " Proust, Temps Retrouvé. ${ }^{10}$

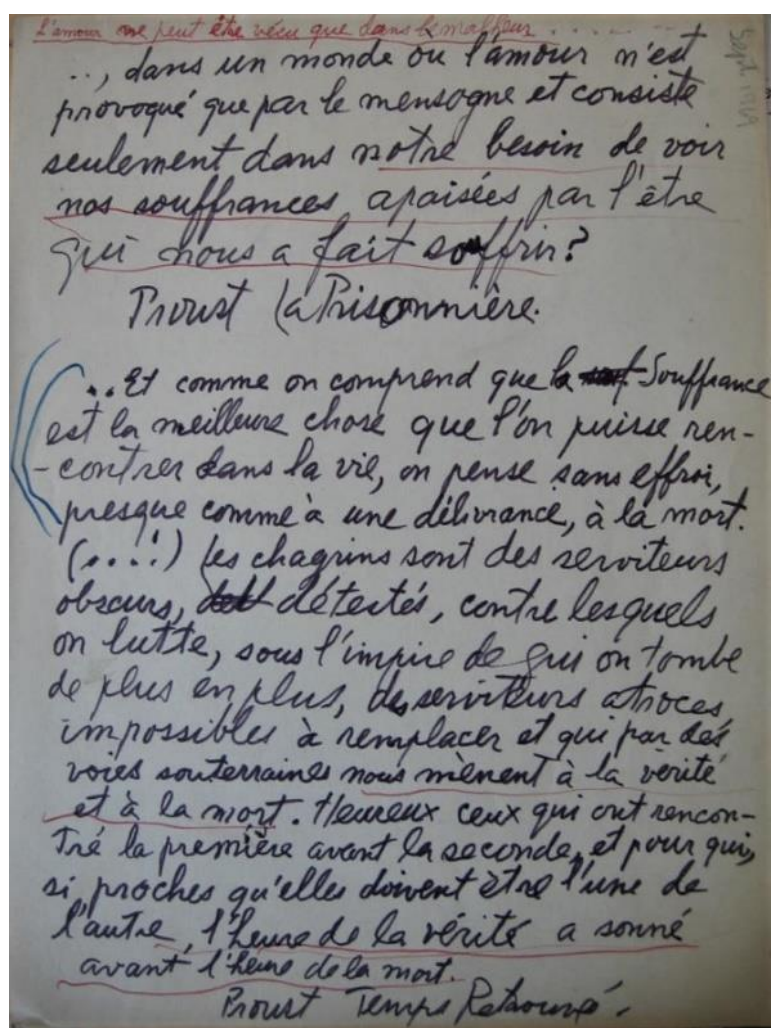

Fuente: Archivo Personal Luis Barragán. Fundación de Arquitectura Tapatía Luis Barragán

Sin embargo, hay otros contendidos recurrentes en los que Barragán prestaba su atención y que, al extrapolarlos con las ideas de Gaos sobre la Publicidad y el predominio de la vida pública sobre la privada en la vida moderna, revela no nada más un paralelismo que desvela la consistencia ideológica detrás del término de publicidad que Barragán adoptó para explicar su obra, sino también un conjunto de reflexiones que coinciden en la pertinencia del rol espiritual del arte en los tiempos modernos. Cabe señalar que tanto Gaos como los autores que Barragán frecuentaba en su biblioteca, se remontaron a la tradición antigua del cuidado de sí y del alma para delimitar la vida humana en su doble posibilidad de existencia, entre la caída y la salvación, y desde esta disyuntiva optar por la conversión que lo abre hacia su consciencia plena y auténtica. ${ }^{11}$

De esta forma, los contenidos e ideas que Barragán recuperaba de los autores de su biblioteca se han estructurado para su exposición bajo esta lógica de la tradición del cuidado. Así, en una primera parte se explicarán aquellas ideas en las que Barragán coincide respecto a la situación de caída del hombre moderno -que para Gaos corresponde al fenómeno de la secularización de la vida-, su

ciertas luces en unas obras determinadas y los usaba como método de reflexión, de meditación sobre los temas que más le interesaba". (Entrevista realizada por el autor del artículo el día 23 de marzo del 2012 a Juan Palomar Verea, en la ciudad de Guadalajara, México).

${ }^{10}$ Citas que transcribía Barragán en una hoja de la obra de Temps Retrouvé de Marcel Proust. Documento consultado en el Archivo Personal de Luis Barragán en Casa-Museo Luis Barragán, Ciudad de México.

${ }^{11}$ La Tradición del cuidado de sí y del alma que se inició desde la época de Platón, fue practicada por los estoicos, posteriormente olvidada por la filosofía escolástica y luego recuperada por Pascal, Schopenhauer, Nietzsche y más tarde por Heidegger. Esta tradición supone que la dinámica de la vida humana tiende a estar absorta en sus preocupaciones, deseos y pasiones por factores económicos y materiales. No obstante, el ser humano tendrá la opción por reconvertir su mirada hacia su interior, lo cual le permite discernir entre aquellos aspectos del exterior que perjudican al alma. Esto posibilita una liberación auténtica del alma (Escudero, 2016).

ACE, 16 (4.7) CC BY-ND 3.0 ES | UPC Barcelona, España La crítica de Barragán hacia la publicidad de la vida moderna y su visión sobre la espiritualidad del arte encarnada en su obra arquitectónica: 194.0-1980. DOI http://dx.doi.org/10.5821/ace.16.47.9051 
inmersión en el mundo tecnocrático e instrumental y sus predilecciones por las situaciones de la mundanidad. Posteriormente, se expondrán las ideas que Barragán subrayaba en torno a la vida pública y su tendencia a alejar al hombre de sí mismo, de su intimidad, provocando en él temor y sufrimiento - proceso que como bien hemos visto corresponde a la Publicidad. Y, por último, se describirán las ideas en las que Barragán focalizaba su atención en torno a la opción del hombre por redimirse y liberarse de la angustia a través de la vida privada o la intimidad como bien definía Gaos y que solo era posible a través de la actividad creativa del arte, de la vida mística y del encuentro con la naturaleza.

\subsection{Publicidad y caída: el sufrimiento derivado de la fe hacia el progreso cientifico}

Para 1976 (momento en que Barragán se entrevistó con Elena Poniatowska), el arquitecto mexicano estaba familiarizado con una de las obras más importantes de la literatura inglesa: La tumba sin sosiego de Cyril Connolly. ${ }^{12}$ Este autor, quien fuera seguidor del grupo literario del Bloomsbury, ha sido considerado entre los novelistas y críticos literarios ingleses más importantes del siglo XX. Su actividad como escritor también le permitió abarcar el ámbito del periodismo, ejercicio que le posibilitó acceder y documentar los principales acontecimientos de la Guerra Civil Española y la Segunda Guerra Mundial.

Bajo el título The unquiet grave, Connolly publicó su obra en 1944. El ejemplar que tenía Barragán en su biblioteca era la traducción al español por la editorial argentina Sur de 1949. La tumba sin sosiego se conforma por un conjunto de divagaciones producidas en un curso de situaciones que el autor vive bajo el pseudónimo de Palinuro (quien fue el timonel de Eneas en el Eneida de Virgilio). Entre la multiplicidad de temas en las que reflexiona Connolly están el progreso de la ciencia y la tecnología; la dualidad humana que encierra la contradicción entre su propia naturaleza y su vocación espiritual; el sentido de la angustia en el género humano; el problema de las pasiones, las diversiones, la superficialidad de la vida mundana, que son propias de la evasión de la muerte y por ende de la situación existencial inauténtica.

Los subrayados de Barragán se concentraron en los apartados donde Connolly equiparaba al ser humano como una máscara egoísta, detrás de la cual no existe otra cosa más que amargura, tedio, culpa y remordimiento, todos ellos alimentados por los placeres más inofensivos. ¿El sentido de ser y existir consistirá en liberarse del yo? Para Connolly, existe una gran tensión entre la moral y el progreso. "La Caída del Hombre, (...) es en realidad la Caída de Dios (Connolly, 1949, pág. 19)”. Pero entonces, ¿cuál sería el sentido del progreso? ¿en qué momento el progreso sustituyó la concepción estática de la felicidad?

En otro texto que seleccionamos La Souffrance et nous de R.P. Sanson de l'Oratoire, hallamos una serie de subrayados que responden a estos cuestionamientos de Connolly. Sanson argumentaba que el sufrimiento humano es por excelencia maestro de vida. El autor sostenía que los sabios luchaban constantemente contra la supremacía del dolor que acosa y hostigaba la vida humana. El sufrimiento, por tanto, es el motor del progreso y de la velocidad-dioses del siglo XX y de la vida mecanizada-, puesto que encausaba los esfuerzos de la razón para hallar soluciones que mejoraran las condiciones de existencia humana. Sin embargo, (Barragán subraya la idea) los sabios también se angustian por

\footnotetext{
${ }^{12}$ Entre los aspectos que Elena Poniatowska mencionaba sobre la figura, personalidad y hábitos del arquitecto, es la alusión del libro de cabecera de Barragán: La tumba sin sosiego (Poniatowska, 1996). De igual forma, en el texto Voces de Tinta Dormida: Itinerarios Espirituales de Luis Barragán. Alfonso Alfaro señala dicho texto como libro de cabecera de Barragán al llamar la atención sobre las huellas de lectura presentes en sus páginas: “Este lector [Barragán] activo no sólo anotaba y subrayaba: tachaba también en ocasiones, o arrancaba páginas (pocas veces), irritado ante afirmaciones que le parecían absurdas o blasfemas (como La Tumba sin Sosiego, uno de los libros de cabecera cuyas múltiples marcas de lectura parecen muestra de una gran empatía y una adhesión entusiasta a la mayoría de las proposiciones del autor ...)" (Alfaro, 1999, pág. 31)
}

ACE, 16 (4.7) CC BY-ND 3.0 ES | UPC Barcelona, España La crítica de Barragán hacia la publicidad de la vida 10 moderna y su visión sobre la espiritualidad del arte encarnada en su obra arquitectónica: 194.0-1980. DOI http://dx.doi.org/10.5821/ace.16.47.9051 
cuestionamientos que intentaban compensar los avances científicos hacia un progreso moral, de lo contrario, el género humano desembocaría hacia una barbarie científica.

La ausencia de la moral como contrapeso del progreso científico según Sanson, conllevaría el riesgo de entumecer progresivamente la capacidad del esfuerzo humano y las más altas facultades que nos vinculan con la vida a través de la comodidad tecnológica. Por tanto, siendo el sufrimiento parte de la existencia humana, la comodidad que trata de exentarnos de todo esfuerzo y dolor, nos encaminaría hacia una regresión. Es así como (subraya Barragán) “el confort nos hará pudrirnos. Mil veces vale el sufrimiento, que, actuando un poco sobre nuestras almas, a la manera de un perfume de embalsamiento de cuerpos, que los preserva de la corrupción de ese sepulcro que es el egoísmo y la falta de vigor en la vida." (Sanson, 1933, pág. 66)

Por tanto, el progreso no es el sentido ni el fin de la vida humana, sino más bien el desarrollo del espiritual humano. Regresando al texto de Connolly, Barragán subraya la idea de que la vida humana es comprensible cuando se considera como una transición del mundo animal al espiritual. La ansiedad, el remordimiento y el sufrimiento devienen en los momentos de fracaso al momento de aspirar a esta espiritualidad. "Por ello (subraya Barragán) siguen de cerca al placer, que desde el momento que no trae cierto avance, perjudica aquella parte nuestra que atañe al crecimiento." (Connolly, 1949, pág. 46)

Para Connolly, la sabiduría de Pascal es la referencia ideal para comprender las razones por las que los placeres y las diversiones nos alejan o desvían de nuestro camino hacia el florecimiento espiritual. No sorprende el hecho de que Barragán se detuviera en analizar este apartado de Connolly, ya que el arquitecto mexicano estaba bien familiarizado con la doctrina de Blaise Pascal. En su biblioteca personal tenía abundantes volúmenes sobre este autor. Llama la atención que, en todos estos textos, además de otros temas, Barragán focalizaba su atención en el tema de las diversiones como evasión de la condición miserable del ser humano.

De esta manera, en el texto de Les Pensées (1947) los subrayados y anotaciones de Barragán están concentrados la mayor parte en el capítulo titulado Conocimiento General del Hombre, donde Pascal reflexionaba sobre la condición de angustia en que el hombre se encuentra en la naturaleza. En este apartado Barragán profundizaba en los mismos contenidos que Connolly trataba en torno a la miseria y la tendencia del ser humano de evadir esta condición a través de le divertissement. Acotaba Barragán lo siguiente: "No pudiendo curar la muerte, la miseria, la ignorancia, a los hombres se les ha ocurrido, para vivir dichosos, no pensar en ellas." (Pascal, 1947, pág. 212), ya que el aburrimiento o la confrontación con la nada desespera y angustia a los seres humanos. Por ello, (subraya Barragán), la causa principal de estas desdichas "consiste en la natural desgracia de nuestra condición débil y mortal, y tan miserable, que nada puede consolarnos, cuando lo consideramos de cerca." (Pascal, 1947, pág. 197)

Sumado a lo anterior, además de las diversiones, de las preocupaciones de la mundanidad y las comodidades que ofrece el progreso de la vida moderna, otro aspecto que obstaculiza la aceptación y resignación de la condición mísera del ser humano es el ambiente "natural" en la que el hombre moderno se realiza y vive: la ciudad.

\subsection{La publicidad de la vida moderna: la angustia, el temor y la evasión}

Para Connolly, la civilización humana es el estado de evolución del hombre que de forma progresiva ha dejado atrás la vida animal. El autor inglés consideraba que un ser civilizado es aquel individuo que ha logrado superar la dualidad entre su alma y su cuerpo a través de la realización de su espíritu. Hoy en día, el ser civilizado habita en las ciudades y esto supone considerar a la ciudad como el ámbito más sutil de la civilización del clima humano, la gloria de la especie humana.

ACE, 16 (4.7) CC BY-ND 3.0 ES | UPC Barcelona, España | La crítica de Barragán hacia la publicidad de la vida moderna y su visión sobre la espiritualidad del arte encarnada en su obra arquitectónica: 194.0-1980. DOI http://dx.doi.org/10.5821/ace.16.47.9051 
No obstante, los seres humanos se han equivocado en el tamaño de las ciudades modernas y en el género de vida que en ellas llevamos. Lo anterior ha desvirtuado severamente la naturaleza civilizada del género humano y el ámbito donde vive y se realiza. A cambio de ello, el hombre moderno habita en una esfera artificial, esclavizado de su ritmo, de su proporción, acarreando miserias y dolencias. (Connolly, 1949)

Adicional a lo anterior, en estos mismos ámbitos artificiales o construidos, prevalece un fenómeno que al parecer ha sido excepcional del siglo XX: el ruido. Este tema, entre muchos otros más, Barragán lo profundizó en el texto titulado Filosofía Perenne del escritor inglés Aldous Huxley publicado en 1945..$^{13}$ En este texto, donde el autor inglés indagaba en la pertinencia actual de la filosofía perenne, los subrayados de Barragán se concentraban en los procesos de mortificación que todo individuo necesita llevar a cabo para fortalecer su vida espiritual y ser partícipe de la Realidad Divina inherente al mundo. Sin embargo (Barragán acota y subraya), dichos procesos se ven enturbiados por un fenómeno particular de nuestra época: el Siglo XX es la Época del Ruido: "Ruido físico, ruido mental y ruido del deseo (...). Y no es extraño, pues todos los recursos de nuestra casi milagrosa tecnología han sido lanzados al general asalto contra el silencio. El más popular e influyente de todos los inventos recientes, la radio, (...) [s]e adentra en la mente y la llena de una Babel de distracciones (...). Hablada o impresa, difundida por el éter o en pulpa de madera, toda la literatura de avisos tiene un solo propósito: no dejar que la voluntad logre nunca el silencio. La falta de deseos es la condición para la liberación y el esclarecimiento. (...) El arte de anunciar es la organización del esfuerzo por extender e intensificar los anhelos - esto es, extender e intensificar la operación de esa fuerza que (...) es la causa principal del sufrimiento y la maldad, y el mayor obstáculo entre el alma humana y su divina Base." (Huxley, 1947, pág. 308)

Esta época del ruido físico y mental que se adentra en lo más profundo de los seres humanos y que impide el esclarecimiento de sus pensamientos en torno a la naturaleza real de sus deseos es propio de la vida pública que imposibilita la vida privada como camino hacia la espiritualidad. La vida pública se vuelve entonces una necesidad, ya que, sin ella, la situación de aburrimiento se hace insostenible y es aquí donde radica el sufrimiento, el temor y la angustia.

De esta manera, el tema de la angustia fue uno de los tantos temas centrales en las lecturas de Barragán. En el texto de Connolly, Barragán subrayaba los párrafos donde el escritor inglés abundaba sobre este tema bajo la expresión del Angst. ${ }^{14}$ Las curas temporales a las que todos los seres humanos están tentados para evadir el angst constituirán siempre una droga peligrosa, y solo su ausencia posibilitaría la felicidad. Por esto, sólo el trabajo del creador, la comunión con la naturaleza y el ayudar al prójimo nos libera del Angst. (Connolly, 1949)

Así, (subraya Barragán) cuando ha dejado de gustarnos el hedor del animal humano, ese momento lúcido cuando los seres humanos dan cuenta de la realidad que queda al ser extraídos de la burbuja los placeres, la esperanza del futuro, la añoranza del pasado, es justo el momento cuando comienza, según Connolly, un pensar claro, un instante en el que el hombre acepta su condena al sufrimiento y se reencuentra con su propia existencia. Barragán subraya la cita con la que Connolly refuerza su argumento de Heidegger (Figura 4): "Para el hombre perdido en el mundo y sus diversiones, esa preocupación es un temor breve y fugitivo. Pero si ese temor cobra consciencia de sí mismo se convierte en angustia (angst), clima perenne del hombre lúcido, en el que vuelve a encontrarse la existencia." (Connolly, 1949, pág. 129)

\footnotetext{
13 La edición que tenía Barragán en su biblioteca pertenece a 1947, traducida al español por la Editorial Sudamericana. Cabe señalar que en su portada está escrita una dedicatoria al arquitecto mexicano con fecha de diciembre de 1948.

${ }^{14}$ La angustia, que puede tomar la forma de remordimiento por el pasado, culpabilidad por el presente y ansiedad por el futuro, es considerada también como la versión primitiva del pecado original, de la caída del hombre.
}

ACE, 16 (4.7) CC BY-ND 3.0 ES | UPC Barcelona, España | La crítica de Barragán hacia la publicidad de la vida 12 moderna y su visión sobre la espiritualidad del arte encarnada en su obra arquitectónica: 194.0-1980. DOI http://dx.doi.org/10.5821/ace.16.47.9051 
Figura 4. Páginas subrayadas y marcadas por Luis Barragán del libro La Tumba sin Sosiego de Cyril Connolly

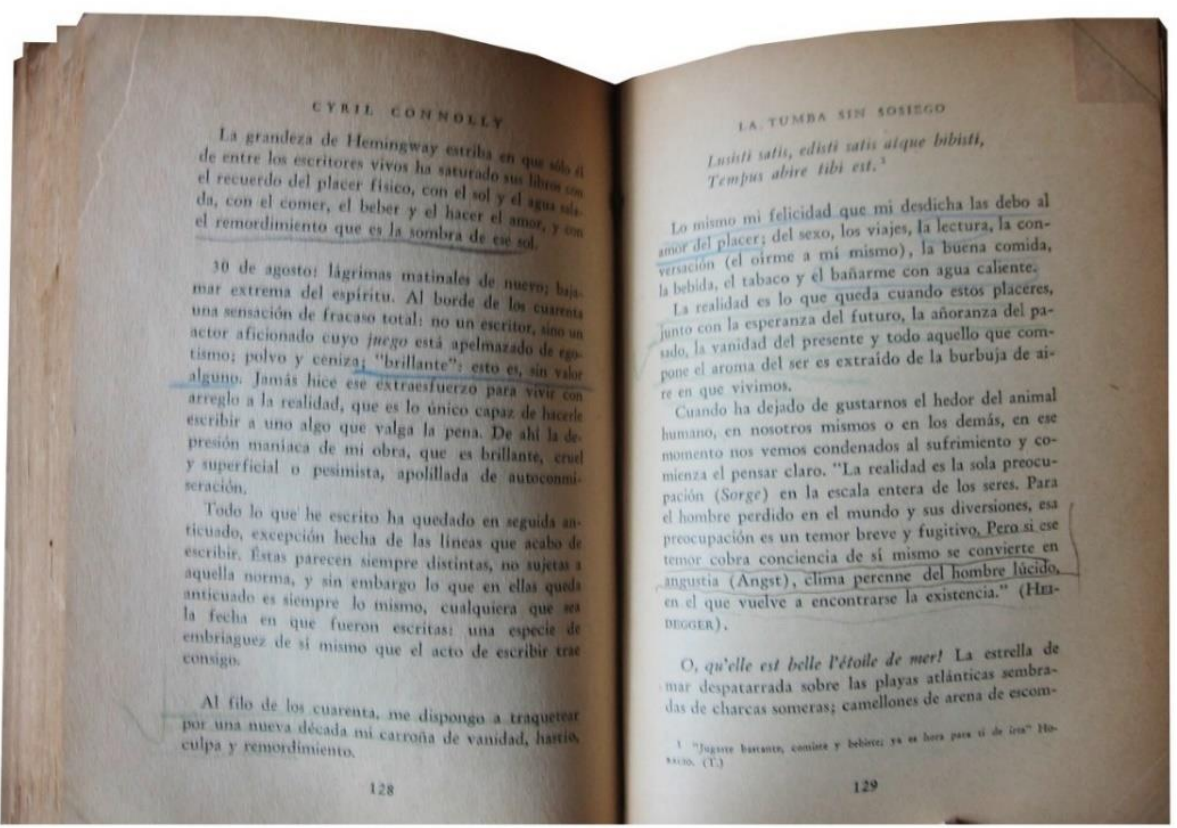

Fuente: Biblioteca de Luis Barragán. Fundación Tapatía de Arquitectura Luis Barragán

\subsection{La vida privada: el arte, la belleza y la espiritualidad}

"Ante todo hay que digerir el sufrimiento inevitable, ACEPTÁNDOLO PLENAMENTE, si no queremos que nos siga envenenando." (Del libro Cerebral de Narciso Isala S.J.) ${ }^{15}$

Es así como el arte y el arrobo místico se vuelven para Connolly los medios a través de los cuales el temor deviene en angustia -entendida como consciencia plena de su propia condición. Como parte de la decadencia del mundo moderno, (que se manifiesta en la degradación de los auténticos valores humanos, en la carencia de una creencia unificadora y la devaluación del papel de la obra de arte) existió una tendencia generalizada en la que el Estado abolía progresivamente la soledad e inspiración privada de los artistas. No obstante, el artista sólo otorgaba resultados en la medida en que su arte fuera producto de un ejercicio íntimo, esencial y derivado de la búsqueda de aquellos remanentes del pasado, del tiempo vivido susceptible de revertirse en materia prima para el arte. Es por esto que (subraya Barragán): "Aun en la comunidad más socializada tiene siempre que haber unos pocos que mejor la [época de decadencia] sirvan permaneciendo solitarios y aislados. El artista, como el místico, el naturalista, el matemático o el "caudillo", contribuyen con su soledad.” (Connolly, 1949, pág. 84)

El arte producido para la comunidad jamás tendrá la misma calidad que la obra artística que brota de la soledad del artista. Por ello, (Subraya Barragán), "un hombre público no puede ser un artista (Connolly, 1949, p. 86)". De esta forma, lejos de servir a la fuerza, al poder, al Estado o a las masas, la función del arte debe estar orientada para elevar y espiritualizar a los hombres y alejarlos de las cosas de la mundanidad de la vida moderna (Sanson, 1933). Y finalmente, la espiritualidad del arte conlleva el cumplimiento de otra condición que Barragán abundaba en el texto de Huxley, que es el valor de la simplicidad como derechura en el alma del artista. ${ }^{15}$ Citas que transcribía Barragán en hojas carta de Narciso Isala S.J. de su libro titulado Cerebral. Documento consultado
en el Archivo Personal de Luis Barragán en Casa-Museo Luis Barragán, Ciudad de México.

ACE, 16 (47) CC BY-ND 3.0 ES | UPC Barcelona, España | La crítica de Barragán hacia la publicidad de la vida moderna y su visión sobre la espiritualidad del arte encarnada en su obra arquitectónica: 1940-1980. DOI: http://dx.doi.org/10.5821/ace.16.47.9051 
Para Huxley, la simplicidad se entiende como el valor que otorga el justo medio donde el alma no es abrumada por lo externo, incapaz de reflexionar y entregada a los interminables refinamientos. La simplicidad es por tanto la tenacidad que impide la conciencia de símismo y que lo encamina hacia un estado de mortificación. De esta manera, encontramos simplicidad y espontaneidad en la personalidad de los artistas, en su espíritu infantil que plasma la espontaneidad y simplicidad en su arte (Huxley, 1947). Así, Barragán coincide con Huxley cuando subraya que, "[u]na elevada realización artística es imposible sin, por lo menos, las formas de mortificación intelectual, emotiva y física apropiadas a la clase de arte que se practica." (Huxley, 1947, pág. 243)

De esta forma, la simplicidad como cualidad artística posibilita la experiencia de la Base Divina. Barragán focalizaba su atención en una cita de Huxley de Visvanatha, cuando explicaba cómo la belleza del arte y de la naturaleza corresponden cualitativamente a la experiencia inmediata de lo Divino, de aquella belleza pura, hermana gemela de la experiencia mística y que solamente la gozan los que son competentes a ello (Huxley, 1947).

En resumen, Barragán consideraba que las hostilidades derivadas del estilo de la vida moderna envolvían a los seres humanos en una realidad "pública" de placeres, trabajo, preocupaciones mundanas, económicas y sociales que acontecían generalmente en los escenarios ruidosos de las grandes ciudades. A pesar de lo anterior, los autores que Barragán seguía en sus lecturas coincidían en la capacidad del ser humano para revertir el sufrimiento en una angustia auténtica, desde la reivindicación del valor sagrado de la vida. Para tal efecto, el arte obtuvo un papel principal en la medida de que estableciera la comunión espiritual entre la realidad de la vida y lo trascendente, tal como como lo sostenía Gaos en la intimidad o privacidad de la vida. Solo en esta privacidad o en comunión con la soledad como bien proponía Connolly, el artista será capaz de realizar este arte que rehúye de lo inmanente, del mundo del más acá, para instalar al ser humano en un clima de consciencia auténtica.

\section{Espiritualidad encarnada: la simplicidad y el carácter sobrio espacial en la arquitectura de Barragán}

“Cómo deben pagarse caro estas curiosidades! Seguramente se cree que el exterior está plegado de peligros, porque aquí todo está dirigido hacia el interior. ¿Los enemigos en un instante pueden surgir y sacudir estas rejas de fierro? ;Cuáles alarmas! Es un jardín con encantos acorazados, que lleva el terciopelo en su dobladillo. El mundo está erizado de demonios. A cada instante pueden venir a asediar la casa." (La Tour du Calife, Les Jardins Enchantés, Ferdinand Bac, 1925)

Durante la década de los años cuarenta la arquitectura mexicana atravesaba por un momento decisivo en la reconstrucción nacional del país. Al tiempo que Barragán iniciaba sus proyectos arquitectónicos y de paisajismo -que para este momento formarían parte de una tendencia que concretaba una postura crítica ante las hostilidades derivadas de la dinámica de la vida moderna-, las doctrinas arquitectónicas encabezadas principalmente por José Villagrán García, Carlos Obregón Santacilia y Mario Pani ${ }^{16}$ instauraban las pautas a seguir para la implementación de proyectos arquitectónicos y urbanos que satisficieron buena parte de las demandas espaciales en sectores como la vivienda, la salud, la infraestructura de comunicaciones, comercio, educación, entre otros.

\footnotetext{
${ }^{16}$ Mario Pani fue considerado como el representante del urbanismo funcional en México. Debido a su formación académica clásica en la escuela Beux Arts de París, fue influenciado por las ideas urbanas de arquitectos como Le Corbusier y Tony Garnier. Por ello, Pani adopta el dogma del movimiento moderno y gracias a los vínculos económicos que su familia mantuvo con los círculos de poder en México, el arquitecto mantuvo una álgida actividad constructiva durante las décadas de los años cincuenta y sesenta (Valenzuela-Aguilera, A. 2020).
}

ACE, 16 (4.7) CC BY-ND 3.0 ES | UPC Barcelona, España La crítica de Barragán hacia la publicidad de la vida moderna y su visión sobre la espiritualidad del arte encarnada en su obra arquitectónica: 194.0-1980. DOI http://dx.doi.org/10.5821/ace.16.47.9051 
Para 1950, el Instituto Nacional de Bellas Artes organizó la primera Exposición de Arquitectura Mexicana Contemporánea, durante la cual el gremio de arquitectos mexicanos reconoció a José Villagrán García como el más importante teórico, maestro y autor de arquitectura mexicana del siglo XX (De Anda, 2006). Con motivo de la inauguración de la exposición, Villagrán dictó una conferencia en la que expuso un resumen histórico de la teoría de la arquitectura, las tendencias arquitectónicas que imperaban en el momento y los propósitos que debían perseguir los arquitectos mexicanos. De igual forma, abogó por una arquitectura respaldada en una teoría moderna que resolviera el Programa General Nacional que englobaba la multiplicidad de reacciones vitales humanas. (Yáñez, 2006)

Sin embargo, a pesar de los esfuerzos por reafirmar lo auténtico mexicano a través de la arquitectura, el gremio de arquitectos mexicanos atravesó por una crisis de identidad y de insatisfacción. Ante esta situación, la arquitectura moderna mexicana había adoptado soluciones que mediante la incorporación de las artes plásticas (muralismo y escultura) en los espacios de los edificios, si pudiera consolidar la identidad mexicana en el discurso espacial abstracto. Esta tendencia de la integración plástica en la arquitectura se manifestó principalmente en los edificios públicos y educativos, como el caso de Ciudad Universitaria de 1952.

Por otra parte, en el ámbito doméstico, la idea de la modernidad se había afianzado en la consciencia colectiva mexicana como sinónimo de confort y accesibilidad a los medios de consumo. Los avances tecnológicos dirigidos hacia la producción de bienes electrodomésticos y el progreso en los medios de comunicación como la radio y la televisión, transformaron significativamente los parámetros del diseño arquitectónico habitacional. De igual forma, la influencia de las publicaciones de arquitectura internacional fue también determinante en el afianzamiento del discurso espacial moderno como sinónimo de progreso. Después de la Segunda Guerra Mundial, México gozaba de un avance considerable en su desarrollo económico, permitiendo la consolidación de la clase media burguesa que gozaba de los medios económicos para acceder a un estilo de vida netamente moderno. De ahí que la arquitectura moderna publicada en estos medios masivos de comunicación jugó el papel como medio de consumo, incorporando de forma inconsciente el lenguaje arquitectónico abstracto, fluido y transparente del Estilo Internacional. (Cruz, 2016)

Es probable que el origen de esta crisis en la arquitectura moderna mexicana tuviera que ver con el hartazgo de la visión instrumental y pragmática de la teoría e historia que regía en la disciplina. Alberto Pérez-Gómez sostiene que la noción de modernidad en México y la teoría arquitectónica moderna como la de José Villagrán García, tuvo sus orígenes desde la visión instrumental francesa de tratadistas de la arquitectura como Guadet y Durand. (Burian, 1998) La funcionalización de la teoría provocó una transformación de carácter tecnológico que dictaminó las formas de realizar arquitectura de manera eficiente y económica, excluyendo las preguntas que refieren a la trascendencia de la disciplina, su posición ética ante la realidad y su dimensión existencial (PérezGómez, 2019).

Esta crisis instrumental en la arquitectura también se resintió en el ámbito mundial de la arquitectura. Por ello, la década de los años cincuenta marcó el auge de arquitectos cuyas obras intentaron concretar una contraposición a la ortodoxia moderna derivada de los cuestionamientos filosóficosontológicos de la propia disciplina.

Por mencionar algunos ejemplos, Alison y Peter Smithson llegaron a proponer arquitecturas que, a través de su materialidad espacial, el usuario pudiera redefinir su consciencia del mundo. Partiendo de las doctrinas existenciales de Jean Paul Sartre y Heidegger, los fundamentos teóricos de los Smithson proponían una arquitectura que través de la agresividad de los materiales, el habitante de sus espacios agudizaba sus sentidos hacia un estado de consciencia viva y reflexiva de su presente. (Williams Goldhagen, 2000) Otro ejemplo es Aldo van Eyck, cuyos viajes por el continente africano a

ACE, 16 (4.7) CC BY-ND 3.0 ES | UPC Barcelona, España | La crítica de Barragán hacia la publicidad de la vida moderna y su visión sobre la espiritualidad del arte encarnada en su obra arquitectónica: 194.0-1980. DOI http://dx.doi.org/10.5821/ace.16.47.9051 
principios de la década de los cincuenta y sesenta trascendieron en la redirección del sentido teórico de su arquitectura, reivindicando el rol que el arte y la cosmovisión de una cultura desempeñaba para la materialización del espacio arquitectónico (Campos Uribe, A. et al, 2020). Y, por último, la exposición de la obra fotográfica de Bernard Rudofsky, Arquitectura sin arquitectos en el MOMA, -que, tras la negativa de Philip Goodwin en 1941, la exposición se aplazó hasta 1964- contribuyó al replanteamiento de las posiciones teóricas de la arquitectura frente a los procesos operativos de la modernización, la devastación del entorno rural y natural. (Scott, 2004)

El caso de Luis Barragán en México no fue una excepción ante esta crisis de la visión instrumental de la arquitectura. Las especulaciones del arquitecto tapatío en torno al fenómeno de la publicidad y su tendencia a sustituir la vida privada por la pública, le permitieron indagar en los replanteamientos ontológicos y éticos que la propia arquitectura requería, en cuanto a su rol histórico y su capacidad por reencausar la misma disciplina hacia un significado claro y hacia una evolución natural de la cultura mexicana moderna.

Similar a las arquitecturas que Ferdinand Bac evocaba en sus descripciones en Les Jardins Enchantés, la arquitectura que Barragán desarrollara a partir de la década de los años cuarenta encarnaba un carácter austero y simple, que posibilitaba una vida doméstica volcada a la intimidad en ambientes privados cerrados a la ciudad y con una relación controlada hacia los jardines interiores.

Para Barragán la coacción entre la Arquitectura del Estilo Internacional y la vida pública era muy claro. Ya desde la mencionada conferencia que impartió Barragán en 1951, el arquitecto mexicano consideraba que los jardines abiertos habían sido creados por el hombre público, que pasa la mayor parte del tiempo evadiendo su "aburrimiento" en público. A cambio, Barragán optaba por jardines privados que posibilitaran la intimidad necesaria para "meditar y permitir a su imaginación el desarrollo de ideas creativas y espirituales.”(Barragán, 1951, pág. 37)

Estas iniciativas comenzaron a tomar forma desde los inicios de la década de los años cuarenta, específicamente en el proyecto de la Casa Ortega (1943), donde la relación entre el paisaje y los ambientes domésticos de la vivienda fue particularmente significativa. La disposición de la planta arquitectónica en forma de "T" posibilitó la presencia permanente de los jardines en buena parte de los espacios interiores. La influencia paisajística de Ferdinand Bac se hizo evidente principalmente en dos aspectos. El primero de ellos consistió en los diversos ambientes singulares que poseían cada área del jardín (e), los cuales posibilitaban diferentes actividades según sus características. La segunda de ellas fue la secuencia espacial que resolvió la transición progresiva entre el interior de la vivienda y el jardín. Como ejemplo, la transición que toma lugar en la entrada del jardín a la casa a través del "corredor" semicubierto (d), que obliga al usuario a travesar en forma de zig-zag un pequeño jardín descubierto contenido entre muros (c), el cual funge como antesala para acceder a un patio interior donde yace un espejo de agua (b). Este patio se relaciona con los "salones" principales de la casa a través de ventanales (a), generando un micro- espacio introspectivo que complementa el carácter aislado, austero y silencioso de lo que vendría ser el núcleo principal de la casa (Figura 5).

En Casa-Estudio (1947), las transiciones entre el jardín y el espacio interior de la vivienda son similares a los que acontece en Casa-Ortega, pero con sutiles diferencias. El "Gran Ventanal" de la estancia es el elemento más importante del ambiente, ya que aporta al espacio la posibilidad de vincular al usuario con la naturaleza. La austeridad y armonía espacial que se percibe en la estancia gracias a la materialidad de los muros que la contienen, inducen al habitante a un ambiente de silencio y rigor, similar a los ambientes monásticos de los complejos católicos religiosos de la época Virreinal de México. El Gran Ventanal fungirá entonces como un marco de reverencia, como una especie de altar que sacraliza la naturaleza y nos relaciona con lo trascendente (Figura 5).

ACE, 16 (4.7) CC BY-ND 3.0 ES | UPC Barcelona, España | La crítica de Barragán hacia la publicidad de la vida moderna y su visión sobre la espiritualidad del arte encarnada en su obra arquitectónica: 194.0-1980. DOI http://dx.doi.org/10.5821/ace.16.47.9051 
Figura 5. (Izquierda) Planta arquitectónica de la Casa Ortega (1943). (Derecha) Ventanal de Casa-Estudio (1947). Luis Barragán

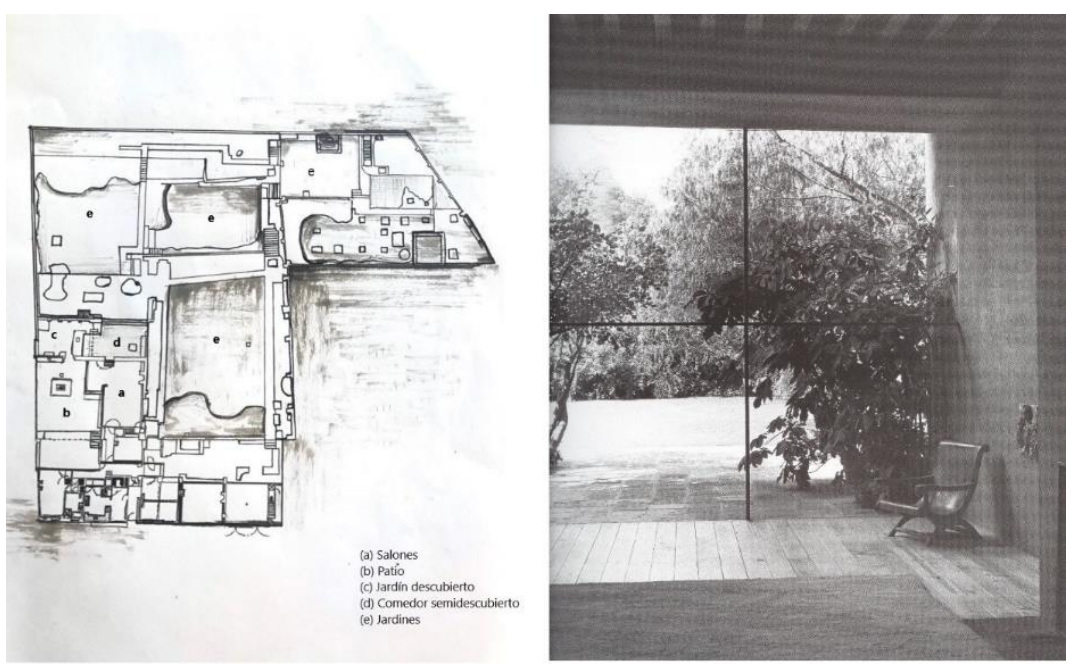

Fuente: D.R. @ LUIS BARRAGAN/PROLITTERIS, Zürich, Switzerland. Dibujo en acuarela: Camila Abella Gutiérrez

A finales de la década de los cuarenta, Barragán proyectó la Casa Prieto López en los Jardines de El Pedregal. La planta arquitectónica de la vivienda está conformada a partir de dos grandes ejes dispuestos en forma de cruz, que distribuyen los espacios privados y públicos de manera independiente. Al mismo tiempo, la composición de la planta genera una relación particular en cada zona del programa arquitectónico con los jardines y patios. El cuadrante localizado al sur-poniente del conjunto, está resuelto por una volumetría dispuesta en forma de "L" que contiene por un lado las habitaciones y servicios complementarios (planta baja y alta) y, por otro lado, la estancia principal y biblioteca. Dicha volumetría delimita un patio en el que Barragán ubicó la alberca de la familia. Por las fotografías de Armando Salas Portugal, las cualidades espaciales de este lugar se logran por el contraste generado entre la austeridad volumétrica y masiva de la vivienda, así como la oposición generada entre la geometría abstracta, desnuda de la superficie del patio contra la naturaleza salvaje que rodea la casa. Pareciera que la arquitectura que se superpone en la flora y en la topografía agresiva y rocosa, funge como un intervalo o refugio artificial ante la hostilidad placentera de la naturaleza que lo rodea (Figura 6).

Figura 6. Casa Prieto López (1948), vista de la fachada frente a la alberca. Luis Barragán

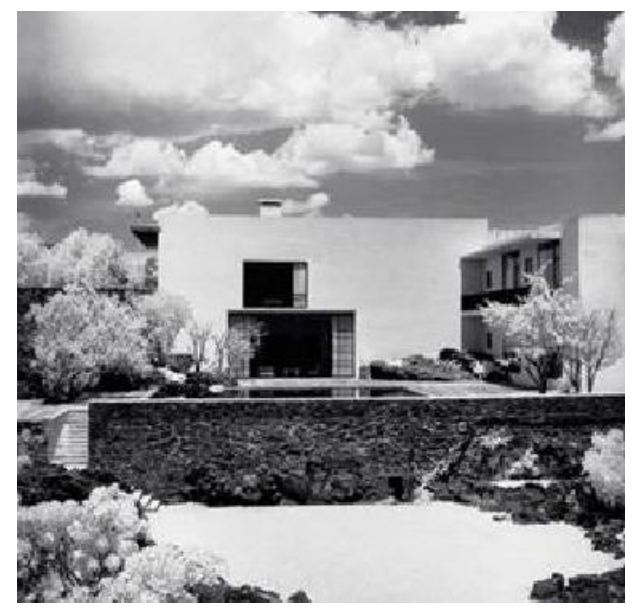

Fuente: D.R. @ LUIS BARRAGAN/PROLITTERIS, Zürich, Switzerland. Fotografía: Armando Salas Portugal

ACE, 16 (4.7) CC BY-ND 3.0 ES | UPC Barcelona, España | La crítica de Barragán hacia la publicidad de la vida moderna y su visión sobre la espiritualidad del arte encarnada en su obra arquitectónica: 194.0-1980. DOI http://dx.doi.org/10.5821/ace.16.47.9051 
Los Jardines de El Pedregal fueron para Barragán el proyecto paisajístico más importante de su carrera profesional. Nuevamente por las fotografías de Armando Salas Portugal, los jardines comunes que Barragán proyectó en dicho desarrollo intentaban sumergir al paseante entre escenarios artificiales abstractos y desoladores que se superponían y enmarcaban el paisaje hostil de la naturaleza del lugar.

Así, al igual que en los jardines de la Casa Prieto López, la confrontación placentera con la topografía rocosa y la fauna de El Pedregal mantenía atento y consciente de su realidad al que lo contemplaba. Así, los diseños paisajísticos realizados hasta este momento (los Jardines del Cabrío y los jardines proyectados en la Casa-Ortega, en Casa-Estudio y en la Casa Prieto López), sumados a los jardines de las áreas comunes del desarrollo urbano de El Pedregal, concretaron soluciones a las preocupaciones planteadas por Barragán en torno al fenómeno de la publicidad en la vida moderna y sus impactos en la prevalencia de la vida pública sobre la privada, en la mencionada conferencia que impartió en Coronado, California.

En 1957, Selden Rodman realizó una entrevista a Barragán y a Mathias Goeritz. Durante este encuentro, Barragán criticaba la visión instrumental de la arquitectura moderna y su incapacidad por atender los aspectos espirituales humanos. Haciendo alusión a los espacios abiertos y los amplios ventanales de las fachadas de los edificios modernos, Barragán sostenía que "en público, la oportunidad para pensar y reflexionar está perdida." (Rodman, 1958, pág. 71)

Dos años antes de la realización de esta entrevista, Barragán había realizado la Casa Gálvez en la Ciudad de México. Además de madurar sus estrategias arquitectónicas que resolvieron la relación entre la vivienda y el paisaje, en el proyecto de la Casa Gálvez se resaltaba el carácter hermético del espacio doméstico. Al visualizar la fachada principal, es de notarse la ausencia de ventanas abiertas de forma frontal a los patios de recibimiento. Solamente hay un ventanal que se abre hacia estas áreas abiertas, pero está protegida por un gran muro rosa que funge como pantalla que refleja la luz hacia al interior. Los espacios públicos de la planta baja y las recámaras principales se abren solamente hacia el jardín interior de la casa y hacia sus terrazas-azoteas cerradas por amplios muros. Así, la compartimentación espacial de la planta refuerza una dinámica de vida doméstica privada, incomunicada con el mundo exterior de la ciudad y fuertemente vinculada con la naturaleza del paisaje con la que interactúa (Figura 7).

Figura 7. Casa Gálvez, (1955). Vista panorámica de terrazas y jardines. Luis Barragán

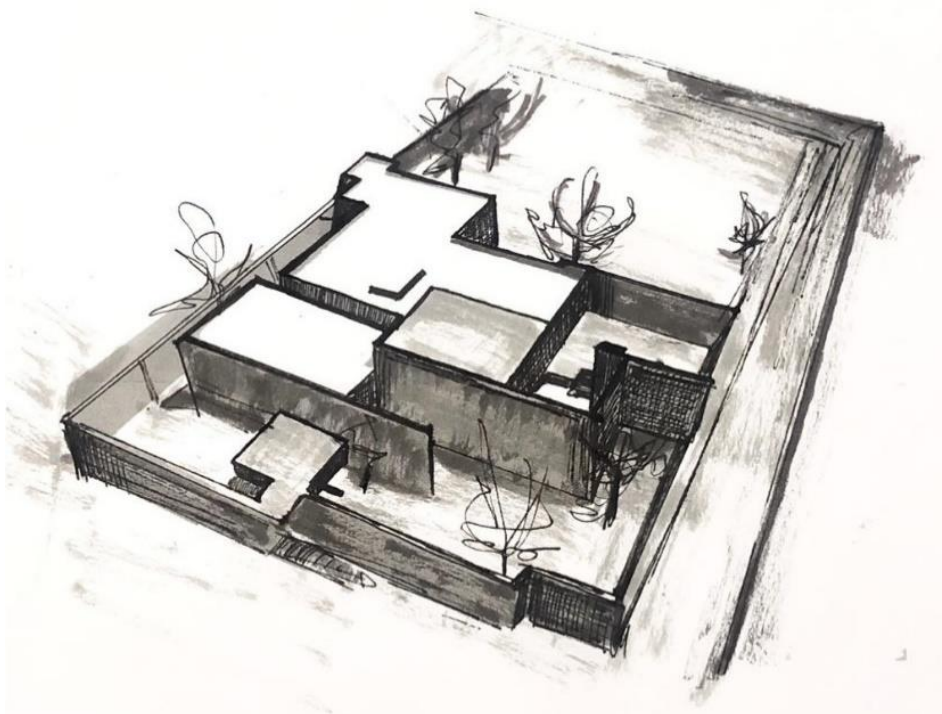

Fuente: D.R. @ LUIS BARRAGAN/PROLITTERIS, Zürich, Switzerland. Dibujo en acuarela: Camila Abella Gutiérrez

ACE, 16 (4.7) CC BY-ND 3.0 ES | UPC Barcelona, España | La crítica de Barragán hacia la publicidad de la vida moderna y su visión sobre la espiritualidad del arte encarnada en su obra arquitectónica: 1940-1980. DOI: http://dx.doi.org/10.5821/ace.16.47.9051 
Siete años después, Barragán criticaba nuevamente los grandes ventanales de los edificios y casas en México. Según Barragán, la vida pública propiciaba el círculo vicioso entre la generación de arquitecturas abiertas, poco acogedoras y gente incapaz por acogerse en su vida íntima. Una casa cuya fachada de cristal exhibe sus interiores y la forma de vivir de los habitantes era síntoma de una sociedad cuya intimidad y vida interior no estaba entre sus formas de vida, sino más bien, aspiraban a llevar el tipo de vida pública recreativa a su vida doméstica. (Rodman, 1958)

En relación a esta entrevista, entre 1966 y 1968, Barragán desarrolló las Cuadras de San Cristóbal a las afueras de la Ciudad de México. Dicho complejo constaba de una vivienda (a), establos (b), zonas de pastura (c) y jardines (d). Respecto a la vivienda, Barragán resolvió la composición de la planta en base a dos ejes dispuestos en forma de cruz, conformando cuatro cuadrantes en los que dispuso patios, jardines y explanadas con características y propósitos distintos. En los cuadrantes localizados al lado poniente, Barragán ubicó dos jardines interconectados por una sutil puerta. El jardín norponiente se caracteriza por su densa vegetación y sus recorridos sinuosos que otorgan a este espacio un carácter íntimo. En el jardín sur-poniente se ubicó la alberca (e) y la zona de esparcimiento privado de la familia. En este espacio exterior, la privacidad se logra por el confinamiento de la densa vegetación que rodea una parte de su perímetro y en el lado opuesto, a través de los espacios semicubiertos de las áreas de las recámaras y el pórtico de descanso (f) (Figura 8).

Figura 8. Planta arquitectónica de las Cuadras de San Cristóbal (1966-1968). Fachada de la Casa de la familia Egerstrom. Luis Barragán

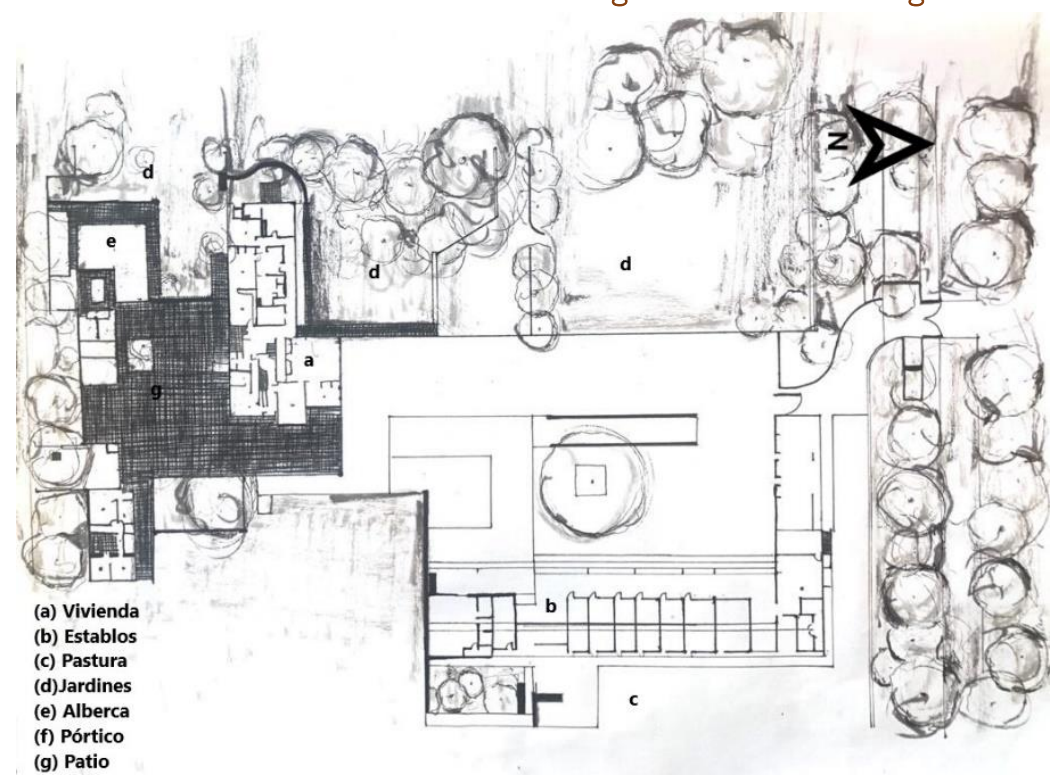

Fuente: D.R. @ LUIS BARRAGAN/PROLITTERIS, Zürich, Switzerland. Dibujo en acuarela: Camila Abella Gutiérrez

Por último, es importante destacar el grado de cerramiento que posee la casa frente al complejo de los establos y otras zonas. La apertura de la vivienda hacia el exterior se genera de manera abierta únicamente en los espacios privados que se comunican con los jardines anteriormente descritos. Contrariamente, en el lado oriente de la planta, el grado de cerramiento es casi hermético. En la explanada ubicada al sur-oriente de la vivienda, Barragán conformó un patio de recepción (g). Desde éste, se aprecia la volumetría escultórica, austera y cerrada de la fachada en color blanco. Los únicos vanos son de la entrada principal que se enmarca gracias a una escalinata, una ventana larga y horizontal cuya transparencia se tamiza a través de una celosía metálica y una puerta adicional que se oculta a través de un pasillo generado entre el volumen de la casa y un muro. El único ventanal que se divisa en esta zona es el que está ubicado en el cuadrante nor-oriente, el cual abre la perspectiva hacia los establos y la alberca de los caballos desde el interior de la vivienda (Figura 9).

ACE, 16 (4.7) CC BY-ND 3.0 ES | UPC Barcelona, España La crítica de Barragán hacia la publicidad de la vida 19 moderna y su visión sobre la espiritualidad del arte encarnada en su obra arquitectónica: 194.0-1980. DOI: http://dx.doi.org/10.5821/ace.16.47.9051 
Figura 9. Casa de la familia Egerstrom en las Cuadras de San Cristóbal (1966-1968). Luis Barragán

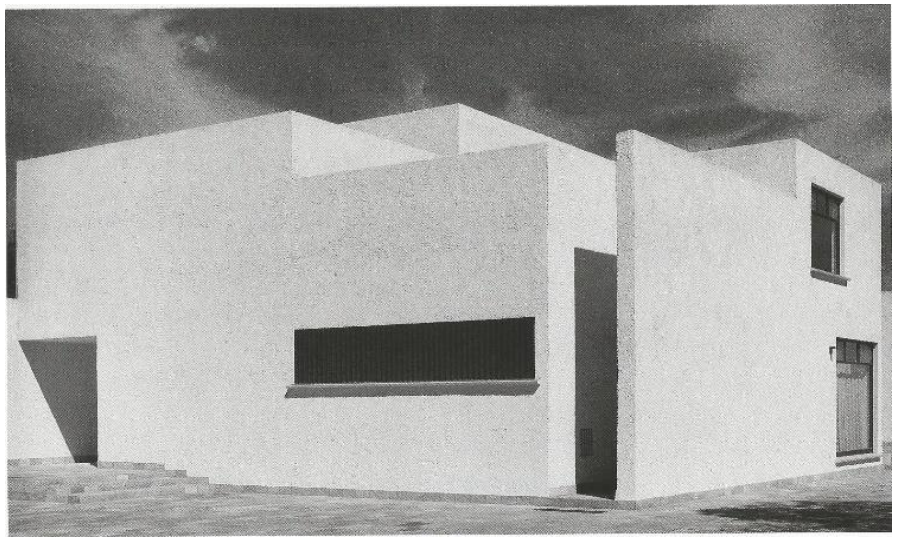

Fuente: D.R. () LUIS BARRAGAN/PROLITTERIS, Zürich, Switzerland. Fotografía: Armando Salas Portugal

En el mismo año que Barragán finalizaba su obra de las Cuadras de San Cristóbal, en una entrevista con Clyve Bamford Smith, mencionaba que: "En una casa con vistas sobre la ciudad sus dueños la muestran a sus visitas, pero no la viven. (...) A la gente le gusta salir a la calle todo el tiempo, las casas no son acogedoras, no detienen a la gente ... los jardines son exclusivamente para alegrar las calles y avenidas. Son jardines que nos enseñan que la vida pública nuestra es un error (...). La gente ha tratado de llevar el tipo de vida pública a su casa (...): no aguantan la casa, quieren convertirla en club (...). La vida privada está siendo relevada y ya no es cosa de nuestra época.” (Bamford, 1968, pág. 6)

En relación a la cita anterior, en 1976 Barragán proyectaba la Casa Gilardi, dentro de la Ciudad de México. Pese a las dimensiones alargadas del terreno, el proyecto se conformó a partir de un patio interior que configuraba un lugar apropiado para un árbol de jacaranda preexistente. Así, el recorrido de los espacios domésticos de la planta baja hacia la piscina/comedor, a través del gran pasillo bañado en luz amarilla, contornean este patio, el cual se revela una vez que el habitante llega a este espacio. Las terrazas de la planta alta y la zona común cobran sentido por su relación con el patio interior que, por la sobriedad de sus muros ciegos y simplicidad compositiva, evocan un clima de tranquilidad que aísla al habitante del tumulto de la vida exterior de la Ciudad de México (Figura 10).

Figura 10. Casa Gilardi (1976). Árbol de Jacaranda en el patio interior. Luis Barragán

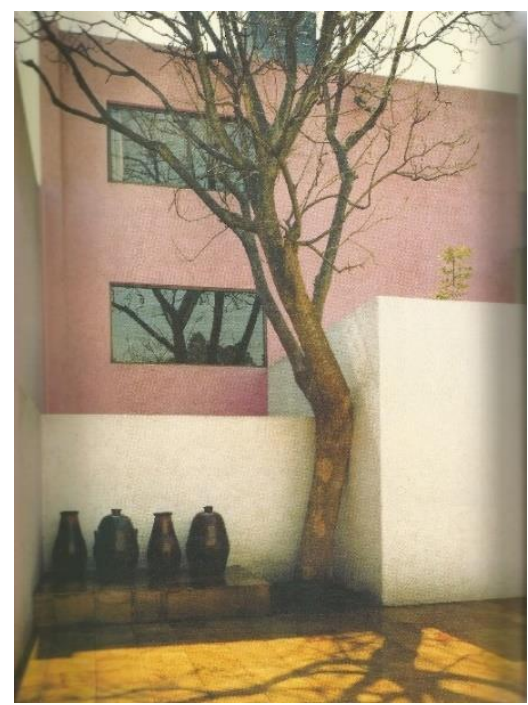

Fuente: D.R. ๑ LUIS BARRAGAN/PROLITTERIS, Zürich, Switzerland. Fotografía Armando Salas Portugal

ACE, 16 (4.7) CC BY-ND 3.0 ES | UPC Barcelona, España | La crítica de Barragán hacia la publicidad de la vida 20 moderna y su visión sobre la espiritualidad del arte encarnada en su obra arquitectónica: 194.0-1980. DOI: http://dx.doi.org/10.5821/ace.16.47.9051 


\section{Conclusiones}

Para Barragán la dinámica de la mundanidad de la vida moderna volcada hacia lo público era coherente con el carácter espacial de la arquitectura del Estilo Internacional. A cambio de la apertura espacial de esta arquitectura, los proyectos de vivienda que Barragán realizaba desde principios de los años cuarenta hasta los setenta gozaban de un carácter compartimentado, cerrado, orientado hacia la vida interior doméstica y excluyente de la vida pública de la ciudad. La transparencia espacial de sus espacios se originaba tan solo hacía el jardín privado, como parte del deseo de introducir el paisaje doméstico a la intimidad del habitante.

Adicional a lo anterior, vale la pena señalar el carácter austero y hermético de las fachadas de Barragán, cuya simplicidad de línea nos remontan a las arquitecturas sin autoría esparcidas por el Mediterráneo y México, y que explican la naturaleza esencial de la visión histórica que Barragán tenía hacia la tradición de la propia disciplina. Ya que lejos de reproducir estilísticamente esta tradición arquitectónica, la estrategia de Barragán se dirige más hacia un camino que reivindicaba de forma crítica, el carácter cerrado, sobrio y austero espacial de la tradición arquitectónica mexicana y mediterránea en la edificación moderna, con miras de reincorporar en el quehacer de la arquitectura las preocupaciones éticas-estéticas, redirigiendo los usos y costumbres domésticos modernos hacia formas de vidas más auténticas, íntimas, espirituales e inscritas en la tradición del cuidado del alma.

La arquitectura de Barragán, por tanto, encarnó la misión espiritual del arte a través de una estética espacial que, además de establecer un diálogo con el ambiente cultural y tradicional del momento, se fundamentó en los preceptos éticos de un pensamiento generalizado y global que cuestionaba los modos en que los procesos de modernización se llevaban a cabo. Esta tendencia favoreció los replanteamientos teóricos establecidos hacia direcciones ontológicas que reconsideraron la disciplina en su momento, redefiniendo su significado ético, su relación con la historia y su sentido espiritual que le dio origen.

Según Marshal Berman, ser moderno implica una experiencia vital inmersa en un ámbito general que promete poder, alegría y crecimiento, pero al mismo tiempo, una amenaza que potencialmente destruye todo lo que somos (Berman, 2006). Para Barragán, la modernidad ya no era una doctrina si no un hecho, una experiencia, "el mundo está erizado de demonios", así lo escribía Ferdinand Bac en otro de los libros de cabecera de Barragán, Les Jardins Enchantés.

Conflicto de intereses: El autor declara que no hay conflicto de intereses.

\section{Bibliografía}

Alfaro, A. (1999). Voces de Tinta Dormida: Itinerarios Espirituales de Luis Barragán. Artes de México, (23), 28-47.

Bac, F. (1925) Les Jardins Enchantés, Paris, Louis Conard.

Barragán, L. (1932) Sobre Ferdinand Bac y Guadalajara. En, Riggen Martínez, Antonio. (Ed), Luis Barragán: escritos y conversaciones, El Escorial, El Croquis Editorial, 2000, pp. 18-19.

Bamford Smith, C. (1968). Luis Barragán. Entrevista sobre el cuestionario (1968). 9p. Documento del Archivo Personal, Caja 14, carpeta 25, IV 3-2.

ACE, 16 (4.7) CC BY-ND 3.0 ES | UPC Barcelona, España | La crítica de Barragán hacia la publicidad de la vida 21 moderna y su visión sobre la espiritualidad del arte encarnada en su obra arquitectónica: 194.0-1980. DOI http://dx.doi.org/10.5821/ace.16.47.9051 
Barragán, L. (1938) Reflexiones sobre la arquitectura moderna en México, D.F. y EEUU. En, Riggen Martínez, Antonio. (Ed.), Luis Barragán: escritos y conversaciones, El Escorial, El Croquis Editorial, 2000, pp. 20-21.

Barragán, L. (1951) Gardens for Environment. Jardines del Pedregal. En, Riggen Martínez, Antonio. (Ed.), Luis Barragán: escritos y conversaciones, El Escorial, El Croquis Editorial, 2000, pp. 36-40.

Barragán, Luis. (1958) La cena de los aforismos, México, Edición no comercial, Alcancía.

Bayón, D. (1975) Luis Barragán y el regreso a las fuentes. En, Riggen Martínez, Antonio. (Ed.), Luis Barragán: escritos y conversaciones, El Escorial, El Croquis Editorial, 2000, pp. 96-102.

Berman, M. (2006) Todo lo sólido se desvanece en el aire. La Experiencia de la Modernidad. México D.F. Siglo XXI Editores, S.A. de C.V.

Burian R.E. (1998). México, modernidad y arquitectura. Entrevista con Alberto Pérez-Gómez. En, Burian R., E. (Ed). Modernidad y Arquitectura en México, (pp. 11-59), Barcelona, Gustavo Gili S.A.

Campos Uribe, A.; Pastor, M. de M.; Lacomba Montes, P. y Martínez Ventura, J. (2020). Multiculturalism in Post-War architecture: Aldo van Eyck and the Otterlo Circles. ACE: Architecture, City and Environment, 14(42), 7033. DOI: http://dx.doi.org/10.5821/ace.14.42.7033

Connolly, C. (1949) La tumba sin sosiego, Buenos Aires, Sur.

Cruz González Franco, L. (2016). La casa en la Ciudad de México en el siglo XX. Un recorrido por sus espacios. Ciudad de México, Universidad Nacional Autónoma de México, Facultad de Arquitectura.

Cuervo Sánchez, A. (2016). El pensamiento político de José Gaos. La Crítica del Totalitarismo. Pensamiento: Revista de investigación e Información filosófica, 72, 272. DOI: http://dx.doi.org/10.14422/pen.v72.i272.y2016.012

De Anda, E. (2006) Historia de la arquitectura mexicana. Barcelona, Editorial Gustavo Gili.

Escudero, J.A. (2016) Guía de lectura de Ser y Tiempo de Martin Heidegger, Barcelona, Herder Editorial, S.L.

Fernández, J. (1983) Textos de Orozco, Ciudad de México, Universidad Nacional Autónoma de México, Dirección General de Publicaciones.

Gaos, J. y Larroyo, F. (1940) Dos ideas de la filosofía: pro y contra de la filosofía de la filosofía. Recuperado de http://www.cervantesvirtual.com/obra-visor/dos-ideas-de-la-fil.html

Gaos, . (1993). Curso de Metafísica 1944, México, Universidad Autónoma del Estado de México.

Gaos, J. (1957) Diez por ciento, México, D.F. Tezontle.

Garciadiego, J. (2016) El fondo, la Casa y la introducción del pensamiento moderno en México, Ciudad de México, Fondo de Cultura Económica.

Huxley, A. (1947) Filosofía Perenne, Buenos Aires, Editorial Sudamericana (Tr. C.A. Jordana).

ACE, 16 (4.7) CC BY-ND 3.0 ES | UPC Barcelona, España | La crítica de Barragán hacia la publicidad de la vida moderna y su visión sobre la espiritualidad del arte encarnada en su obra arquitectónica: 194.0-1980. DOI http://dx.doi.org/10.5821/ace.16.47.9051 
Noelle, L. (1996) Luis Barragán, búsqueda y creatividad, Colección de Arte no. 49, Primera Edición, México D.F., Dirección General de Publicaciones de la Universidad Nacional Autónoma de México, C.U.

Pérez-Gómez, A. (2019) Tránsitos y fragmentos. Textos Críticos de Alberto Pérez-Gómez, Ciudad de México, Universidad Nacional Autónoma de México.

Orendáin, M.A. (2004) En busca de Luis Barragán, México, Ediciones de la Noche.

Pascal, B. (1947) Les Pensées, Paris, La Bonne Complaigne.

Poniatowska, E. (1996) Luis Barragán. (diciembre 1976). En, Poniatowska, Elena, Todo México. Tomo 1. México, D.F., Séptima Edición, Editorial Diana.

Ramírez Ugarte, A. (1962) Los Jardines de Luis Barragán. 15p. Documento del Archivo sin catalogación.

Rodman, S. (1958) Diario Mexicano. Los Conquistadores Conquistados. En, Riggen Martínez, Antonio. (Ed.), Luis Barragán: escritos y conversaciones, El Escorial, El Croquis Editorial, 2000, pp. 69-71.

Romanell, P. (1952) Making of the Mexican Mind: A study in recent Mexican Thought, Lincoln, Nebraska, University of Nebraska Press.

Sanson, R.P. (1933) La Souffrance et nous, Paris, Flammarion.

Scott, D. (2004). Revisitando Arquitectura sin arquitectos. Revista Block, 6, 80-85.

Valenzuela-Aguilera, A. (2020). La metacentralidad y sus contradicciones. Tlatelolco como espacio paradoxal de resistencia en la Ciudad de México. ACE: Architecture, City and Environment, 14(42), 8224. DOI: http://dx.doi.org/10.5821/ace.14.42.8224

Williams Goldhagen, S. (2000) Freedom's Domiciles: Three projects by Alison and Peter Smithson. En, WILLIAMS GOLDHAGEN, SARAH y LEGAULT, RÉJEAN. (eds), Anxious Modernisms: experimentation in postwar architectural culture (pp. 75-95). Montréal, The Canadian Center for Architecture.

Yáñez, E. (2006) Arquitectura, teoría, diseño, contexto, México, D.F., Editorial Limusa, S.A. de C.V. Grupo Noriega Editores.

ACE, 16 (4.7) CC BY-ND 3.0 ES | UPC Barcelona, España | La crítica de Barragán hacia la publicidad de la vida moderna y su visión sobre la espiritualidad del arte encarnada en su obra arquitectónica: 194.0-1980. DOI http://dx.doi.org/10.5821/ace.16.47.9051 